\title{
Lateral flow immunoassay for small-molecules detection in phytoproducts: a review
}

\author{
Poomraphie Nuntawong ${ }^{1} \cdot$ Waraporn Putalun ${ }^{2,4} \cdot$ Hiroyuki Tanaka $^{3} \cdot$ Satoshi Morimoto ${ }^{1} \cdot$ Seiichi Sakamoto ${ }^{1}$ (D)
}

Received: 24 November 2021 / Accepted: 29 January 2022 / Published online: 16 February 2022

(c) The Author(s) 2022

\begin{abstract}
Phytoproducts are involved in various fields of industry. Small-molecule $(\mathrm{Mw}<900 \mathrm{Da})$ organic compounds can be used to indicate the quality of plant samples in the perspective of efficacy by measuring the necessary secondary metabolites and in the perspective of safety by measuring the adulterant level of toxic compounds. The development of reliable detection methods for these compounds in such a complicated matrix is challenging. The lateral flow immunoassay (LFA) is one of the immunoassays well-known for its simplicity, portability, and rapidity. In this review, the general principle, components, format, and application of the LFA for phytoproducts are discussed.
\end{abstract}

Keywords Immunoassay · Immunochromatographic strip test $\cdot$ Lateral flow immunoassay $\cdot$ Plant secondary metabolites · Hapten · Small molecules

\section{Introduction}

Phytoproducts are the substances, extracts, or compounds obtained from plants. They are in high demand in several industries, including medicine, cosmetics, and foods [1]. Plant secondary metabolites are an important part of phytoproducts [2]. The secondary metabolites of plants are generally small-molecule organic compounds $(\mathrm{Mw}<900 \mathrm{Da})$ produced by plants but not directly involved in their growth and development $[1,3,4]$. The secondary metabolites are produced for long-term plant survival against herbivores, pests, pathogens, and the attraction of pollinators. The role of certain secondary metabolites remains unclear $[1,3-5]$.

Seiichi Sakamoto

s.sakamoto@phar.kyushu-u.ac.jp

1 Graduate School of Pharmaceutical Sciences, Kyushu University, 3-1-1 Maidashi, Higashi-ku, Fukuoka 812-8582, Japan

2 Faculty of Pharmaceutical Sciences, Khon Kaen University, Khon Kaen 40002, Thailand

3 School of Pharmacy, Sanyo-Onoda City University, 1-1-1 Daigakudouri, Sanyo-onoda-shi, Yamaguchi 756-0884, Japan

4 Research Group for Pharmaceutical Activities of Natural Products Using Pharmaceutical Biotechnology (PANPB), National Research University-Khon Kaen, Khon Kaen, Thailand
These compounds have various biological functions, which can be applied in many fields [2]. The quality of phytoproducts is important, particularly when the plants are used in the field of medicine. The level of secondary metabolites is typically measured and used as a quality indicator for phytoproducts $[6,7]$. When plant-based products were used in a particular field, the adulterants and contaminants were highlighted as a global problem [7-11]. Certain products have been spiked with fungicides and/or phytoregulators for agricultural purposes [12]. The excessive intake of these adulterated and contaminated phytoproducts is harmful. Thus, a series of analytical techniques for small-molecules detection such as high-performance liquid chromatography (HPLC), gas chromatography (GC), GC-mass spectrometry detection (GC-MS), and liquid chromatography-mass spectrometry (LC-MS) have been developed. However, these methods require sophisticated equipment, skillful operators, and long operation times. Furthermore, these methods cannot be applied outside the laboratory.

The concept of using immunoassays for small-molecule detection was introduced to surmount these limitations. The assays are based on the specific binding of an antibody and antigen. The enzyme-linked immunosorbent assay (ELISA) relies on this basis. The benefits of this method are its costeffectiveness, simplicity, and sufficient sensitivity, indicating that this immunological approach is useful for secondary metabolite detection [13]. Although the ELISA can solve 
the drawbacks of conventional chromatographic assays, the competitive ELISA is not suitable for certain scenarios and requires improvements. Generally, indirect competitive ELISA (icELISA) comprises five main steps, namely the antigen coating, nonspecific binding blocking, primary antibody reaction, enzyme-labeled antibody reaction, and enzymatic reaction. Hence, at least $4.5 \mathrm{~h}$ is required to complete the general icELISA [13]. Moreover, to read the signal from ELISA, microplate readers that correspond to the signal are required. Given these pitfalls in the current detection systems, the point-of-care test called a lateral flow immunoassay (LFA) was developed. Generally, macromolecules (proteins) or whole cells are the major analytes detected by immunoassays. These analytes can bind to the solid phase (i.e., microplate for ELISA and membrane for LFA) with few or without modification. Thus, non-competitive immunoassays are possible for detection. Moreover, their large and complex structure enables the generation of two different antibodies which recognize different epitopes on the same antigen with ease. This enables sandwich immunoassay format possible when macromolecules and whole cells are used as analytes. The competitive format also can be developed as an optional method for macromolecules and whole cell immunoassays. For small-molecules detection, the immunoassay format and design are slightly different. The competitive format is preferred over non-competitive format since the small molecules are unable to be immobilized directly on the solid phase. The general fabrication of LFA and its application in quality control for phytoproducts are discussed in this paper.

\section{LFA}

There is a wide application of point-of-care tests in environmental science, food, drug, and clinical analyses. "Ready to read" results are provided in a short time. The LFA or immunochromatographic strip test is a point-of-care device, which has been applied in qualitative, semi-quantitative, and quantitative analyses in versatile scenarios for six decades. The LFA is a simplified immunoassay, in which the antibody-reporter molecule conjugates are accumulated on the designated area of the membrane, which is filled with the antigen, and the result can be read-out within several minutes.

In 1956, the first nanoparticle application in immunoassays was initiated during Plotz and Singer's so-called "latex fixation" test, in which the immunological approach was developed without using a paper-based device [14]. Thereafter, the radioimmunoassay (RIA) was developed by Yalow and Berson in 1959 [15], where a paraffin paper-based immunochromatographic device was developed to determine the insulin level in plasma. Afterward, the enzymebased immunoassay was popularized as the replacement of the RIA in the 1960s [16]. The basic idea of immunoassays was continuously refined until the concept of using colloidal gold nanoparticle conjugates in an immunoassay was initiated in 1980 when the strategy called the sol-particle immunoassay was reported [17]. The usage of colloidal gold nanoparticles in immunoassays gained considerable attention in the 1980s because the well-known pregnancy test strip was commercially available and patented [18]. Eventually, the LFA was developed for determining antigens, antibodies, and amplification products of genes [19-22] in several fields. This method is suitable as a point-of-care test, according to the World Health Organization using the criteria of ASSURED (affordable, sensitive, specific, userfriendly, robust, equipment-free, and deliverable) [23]. The criteria were recently revised as REASSURED (real-time connectivity, ease of specimen collection, affordable, sensitive, specific, user-friendly, rapid and robust, equipment-free and environmentally friendly, and deliverable to end-users) [24]. The system has been continuously refined and simplified, enabling non-skilled operators to perform the assay. Various commercially available strip tests for various antigens or antibodies have been launched [25-27]. Although the classical chromatography and ELISA methods offer high accuracy, the LFA is advantageous over them in scenarios where laboratory equipment is not available. Moreover, the assay time is extremely short. This renders the LFA a premium choice for sample screening.

\section{Components of LFA}

Generally, as demonstrated in Fig. 1, the immunoassay is performed on a strip on which many types of materials are assembled. The main components of the strip are described in this section.

\section{Backing card}

This is the part that provides strength to the whole system and enables ease of handling. It is typically fabricated with plastic polymers, such as polyvinyl chloride $[28,29]$ and polystyrene [30]. Herein, the thickness of the backing card was in a wide range of $0.3-0.6 \mathrm{~mm}$ in the form of a piece of plastic sheet or a roll of plastic sheet. The commercially available backing card for LFA typically comes with an adhesive layer, which can be divided into four main areas for attaching the necessary components to the strip.

\section{Sample pad}

This is the component where the sample is applied to initiate the assay. The liquid is transferred through this component to other parts of the strip. The sample pad is typically made from cellulose [31], whereas certain minor 

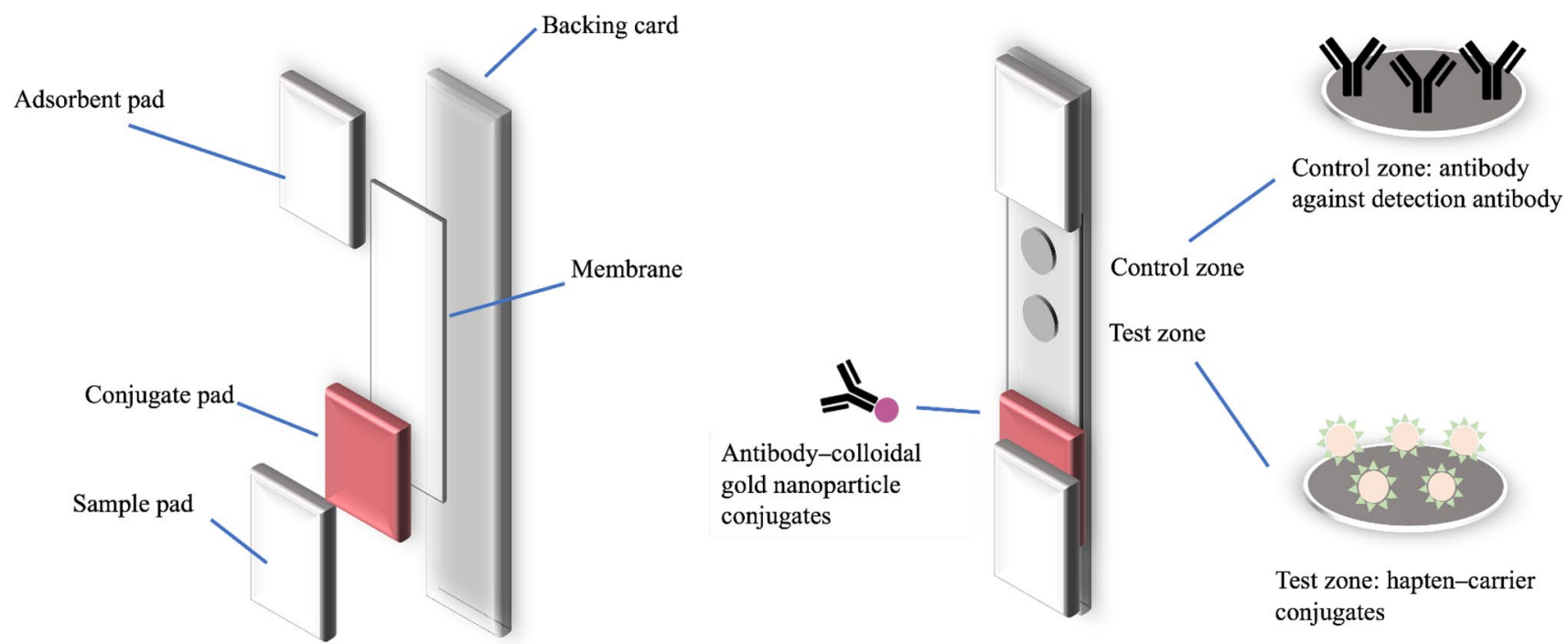

Fig. 1 General components of the LFA and schematic description of each component of the immunochromatographic strip

pads are made from glass fiber [32]. The ideal sample pad continuously transfers the liquid at the designed flow rate. Hence, the homogeneity of the pore size is designed by the specific assay. For instance, samples that do not contain particle or prefiltered could use a homogeneous pore size sample pad, compared with samples that contain coarse materials, such as plant powders, preparations with insoluble ingredients, and whole-cell suspensions that prefer a nonhomogeneous pore size pad for the initial filter effect. When necessary, the sample pad is pretreated with a wetting agent, buffer, protein, or viscosity-enhancing agent. The aim of these pretreatments was mainly to control the flow rate, increase the retention time on the conjugate pad, and increase the reaction time at test and control zones.

\section{Conjugate pad}

Glass fiber is the famous material used for this component. Minor conjugate pads are made from polyester, cellulose, and other materials. It is the space where the antibody-reporter molecule conjugates are accumulated. The ideal conjugate pad should act as a bank of antibody-reporter molecule conjugates, which readily release once the liquid passes through and not permanently retain the antibody-reporter molecule conjugates. In certain LFA formats, this component is omitted, and the antibody-reporter molecule conjugates are directly added into the sample [33, 34].

\section{Membrane}

This is the area where the reaction of the antibody and antigen occurs. This membrane is typically made from nitrocellulose [35]. However, certain strip membranes are made of individually customized cellulose paper [36]. The pore size of the membrane highly affects the sensitivity of the LFA through the capillary flow rate. The reaction time of the antibody and immobilized antigen is high when the flow rate is low, offering a high chance of a reaction. Nevertheless, the experiment time (time until read-out) is equally high in such cases. Therefore, the membrane is chosen based on the balance between sensitivity and assay time. The ideal membrane exhibits low nonspecific adsorption. However, membrane blocking with low protein concentration (e.g., bovine serum albumin (BSA)) can be conducted when necessary. Before use, the membrane can be modified using a wetting agent and buffer to achieve the best condition for assays.

\section{Adsorbent pad}

This is the area to retain excess liquid in the system. The drainage of the excess liquid reduces the backflow of the sample and maintains an even flow rate in the system. Cellulose is typically used as a material for this pad.

The specificity and sensitivity are the important features of the LFA. The specificity is the antibody-related property. However, sensitivity could be affected by components of the LFA. The sensitivity of the test is related to the flow rate of the whole assay. Thus, the components that affect the flow 
rate of the test, i.e., sample pad and membrane play a role on sensitivity controlling. The flow rate of the whole assay could be controlled by the materials pore size, hydrophilicity of the materials, and pretreatment of the materials. Increasing/decreasing the flow rate for sensitivity adjustment is dependent on the format of the assay. For sandwich format, the flow rate needs to be slow enough to obtain the sufficient reaction time. In the competitive format, faster flow rate is not an obstruction for this LFA since the presence of an analyte is evaluated by the absence of the spot. However, the flow rate for competitive assay should be optimized to make the test zone visible in the non-analyte control strips. Even though sensitivity is the important factor of the assay, some LFAs require fast flow rate since the analysis time is also the point of concern as LFA is usually used as rapid test.

\section{Manufacturing process of LFA}

To date, the LFA applied for plant secondary metabolite is not available for mass-production. The mass-production of the LFA is generally applied for the medical diagnosis where the analytes are macromolecules. However, the manufacturing process of LFA is quite similar to the general one. The production of LFA generally initiated from preparation of necessary elements, assembling, cutting, and cassette assembling. The manufacturing process can be a batch-to-batch production or a continuously reel-to-reel production.

\section{Membrane preparation}

The test zone solution (hapten-carrier solution) and control zone solution (antibody against detection antibody) are accurately dispensed to the membrane using the appropriate dispenser, e.g., contact tip dispenser, noncontact pumpdriven solenoid dispensers, and quantitative airbrush-type dispensers. The suitable dispenser is selected by the scale of the production. The reaction line-dispensed membrane is then dried using either in-line drying or batch oven drying. If necessary, the membrane is blocked by the appropriate solution using dipping tank and finally dried prior assemble. The membrane could be prepared with or without backing card in this step.

\section{Conjugate pad preparation}

The conjugate pad is pretreated (if necessary) with appropriate solution and dried prior to the antibody-reporter molecule conjugates dispensing. The conjugate could be dispensed by either dipping tank or the accurate dispenser. The finished conjugate pad is dried prior assembling.

\section{Sample pad preparation}

In some case, the LFA performance is enhanced by sample pad pretreatment. Thus, the sample pad is pretreated with optimized sample pad treatment solution and is then dried prior assemble.

\section{Assembling or lamination}

This is the process that membrane, conjugate pad, and sample pad are assembled into one-piece. Generally, semiautomated laminator is applied in this step in batch-to-batch production while in-line laminator which can laminate the treated elements after treatment is applied for reel-to-reel production.

\section{Strip cutting}

This is the process which the laminated sheet is cut into each strip. The size of the strip varies depending on the design of the strip test. The general cutters for this process are single rotary blade cutter, rotary card cutter, and guillotine cutter.

\section{Cassette assembly}

To increase the ease of handle for the strip, the strip is manually placed into the plastic housing. In some cases, the strip is cover with the soft plastic to enhance the strength of the strip and protect the reaction area against the mechanical force.

\section{General principle of the LFA}

\section{Competitive format}

There is a simple rationale behind the LFA, as demonstrated in Fig. 2. The major assays for small-molecule detection in phytoproducts are based on the competitive immunoassay. The assay commences when the liquid containing the analyte of interest flows through the strip after sample application. The sets of the strip can be provided with the cassette, which contains the sample loading opening that is connected to the sample pad and read-out opening [37-43]. However, the cassette is not required in certain assays. Hence, the sample is applied either into the sample loading opening of the cassette or by directly dipping the sample pad of the strip into the sample solution. The liquid flows through the strip mainly by capillary force [44]. The direction of the flow is the origin of the assay name since the liquid flows laterally through the other compartment when the cassette is provided. In a case where the cassette is absent, the strip typically stands in the glass tube [33] or the microplate [34] where the sample solution or suspension is located. 
Fig. 2 Competitive format of the strip test. The upper section demonstrates the symbolic representation of each compartment. The figure demonstrates the LFA signal in various analyte concentrations. There are two main types of detection zones, which are the spot and band types which demonstrated in the lower section

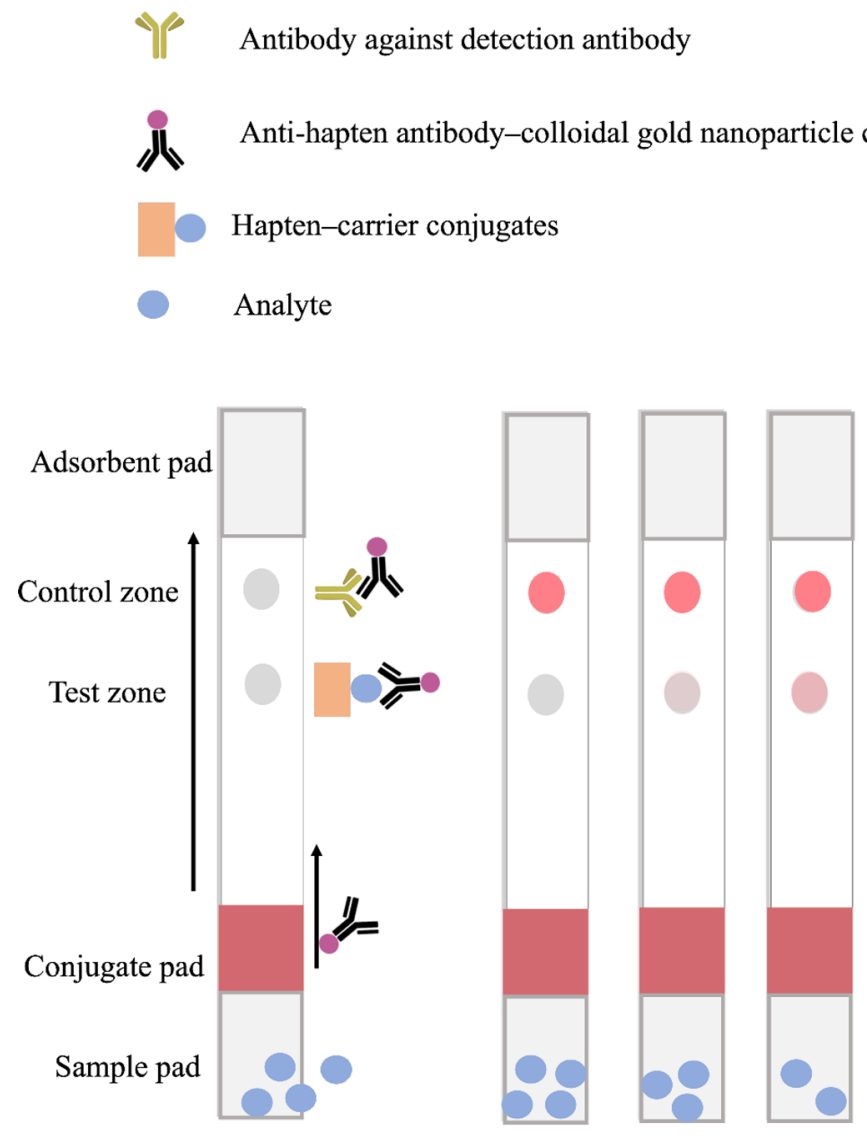

High analyte concentration

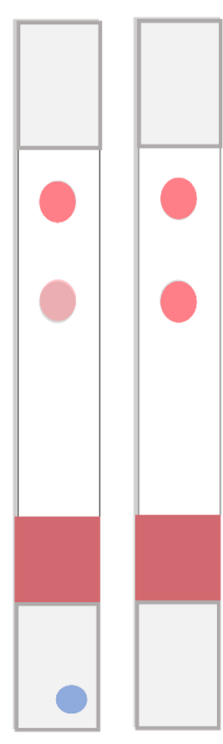

Low analyte concentration

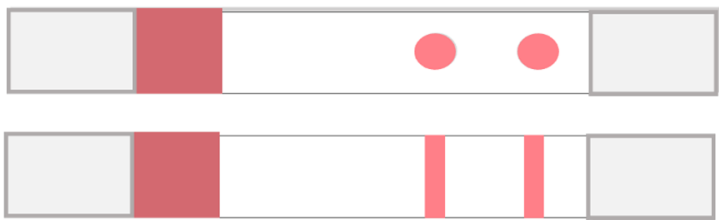

Spot type-reading zones

Band type-reading zones

Therefore, the direction of the flow is antigravity. The highsolubility sample can be directly diluted in the buffer that builds up a suitable environment to interact with the detection system, whereas a moderate- to low-solubility sample can be dissolved using a low-concentration organic solvent as a cosolvent. The sample slowly migrates to the conjugate pad from the sample pad. This contains target-specific antibody-reporter molecule conjugates. In cases where the conjugate pad was omitted, the antibody-reporter molecule conjugates were mixed into the sample with an appropriate amount [33, 34, 45-47]. When the liquid passes through the conjugates reservoir, the antibody-reporter molecule conjugates are slowly released. Few antibodies start to bind with the antigen and move together to the test zone. Test zone is normally filled with hapten-carrier conjugates. Under a high analyte concentration, most antibody-reporter molecule conjugates are filled with analytes in the antibody binding sites.
Thus, the antibody is unable to bind the hapten-carrier conjugates leaving no spot on the strip. Conversely, there is space on the binding sites of antigen-reporter molecule conjugates, which can react with the antigen of immobilized hapten-carrier molecules under a low analyte of interest condition. The accumulation of the reporter molecules on that zone renders the spot visible by color development or fluorescence (depending on the type of reporter molecules). Afterward, the liquid passes through the last zone called the "control zone." This zone is used to indicate the suitability of the system. It is normally immobilized by the antibody, which can react to the antibody-reporter molecule conjugates whether the binding sites are free or not. Thus, in this zone, a spot is always present under the immunochromatography-appropriate condition. The shape, color, and intensity of this zone indicate the abnormalities of the strip test system. The test and control zones can be designed in a 
band or spot-shape. However, the band-shape zones require special equipment to evenly transfer the designated solution onto the desired area [48]. The in-house reagent dispensing machine can be used with proper validation [48-50]. Dissimilar to the spot shape zones, simple biotechnology instruments, such as the pipette, can be used where access to the lateral flow dispenser is limited. The size and shape of the zones can be designed based on the function between the area of the zone and the concentration of antibody-reporter molecule conjugates. The small area of the zones required a minimal number of antibody-reporter molecule conjugates leading to high sensitivity. However, an extremely small area of the zones leads to the invisibility of the zones. Thus, the zone design should be optimized in the individual test. The excess liquid of the system is adsorbed in an adsorbent pad.

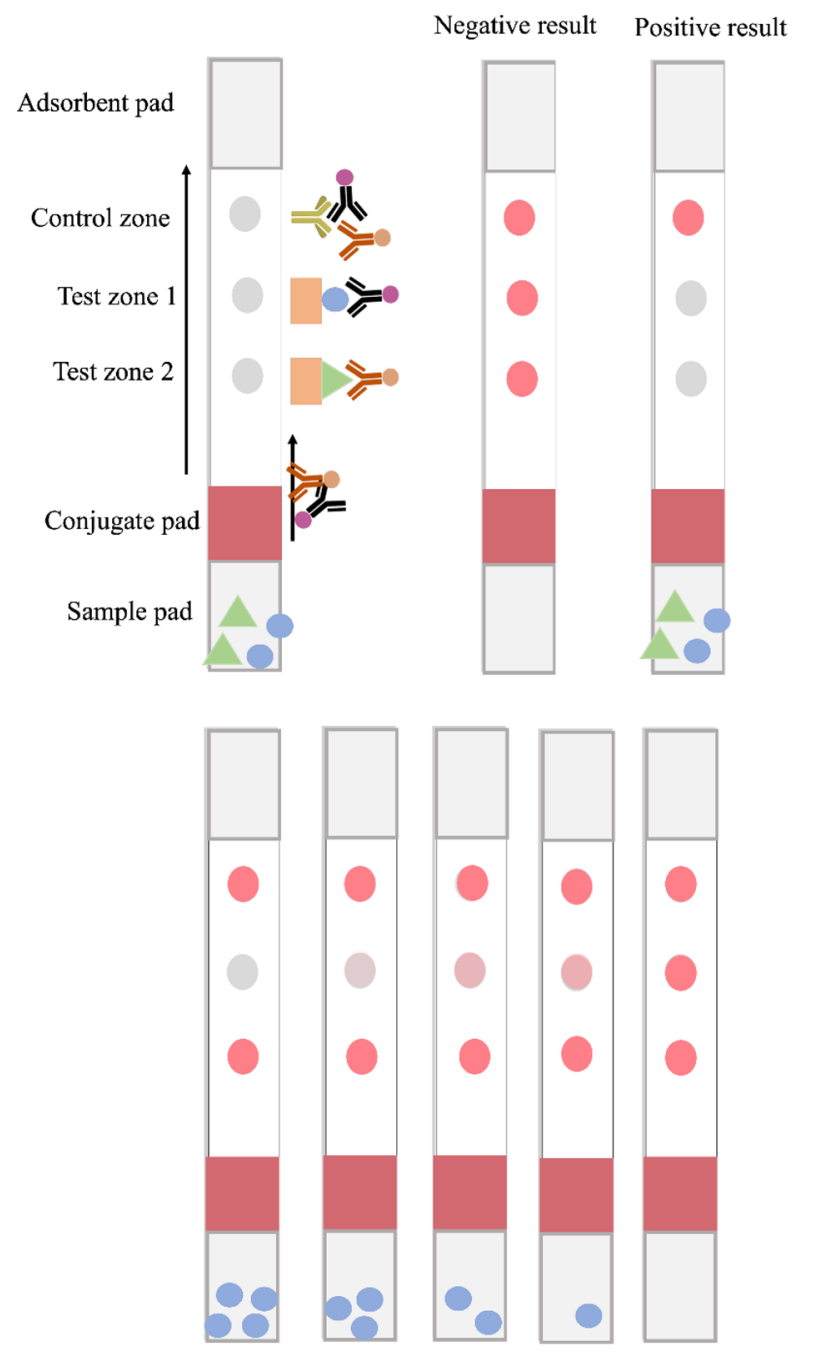

High analyte concentration

Low analyte concentration

Fig. 3 Multiplex competitive format of the strip test. The figure illustrates the multiplex competitive format designed for the simultaneous detection of two analytes. The upper right part demonstrates the sym-
The adsorption protects the unwanted backflow of the liquid in the strip. Generally, the band or spot with the intensity difference can be determined via visual observation. The appropriate reader or interpretation software is used for the intensity measurement in cases where thoroughly precise results are needed.

\section{Multiplex competitive format}

More than one analyte can be detected on an individual strip, as shown in Fig. 3. The principle of this format is identical to the general competitive format. However, more than one antibody that corresponded to the number of analytes of interest are required in this system. The antibodies are individually embedded on the detection probe in the

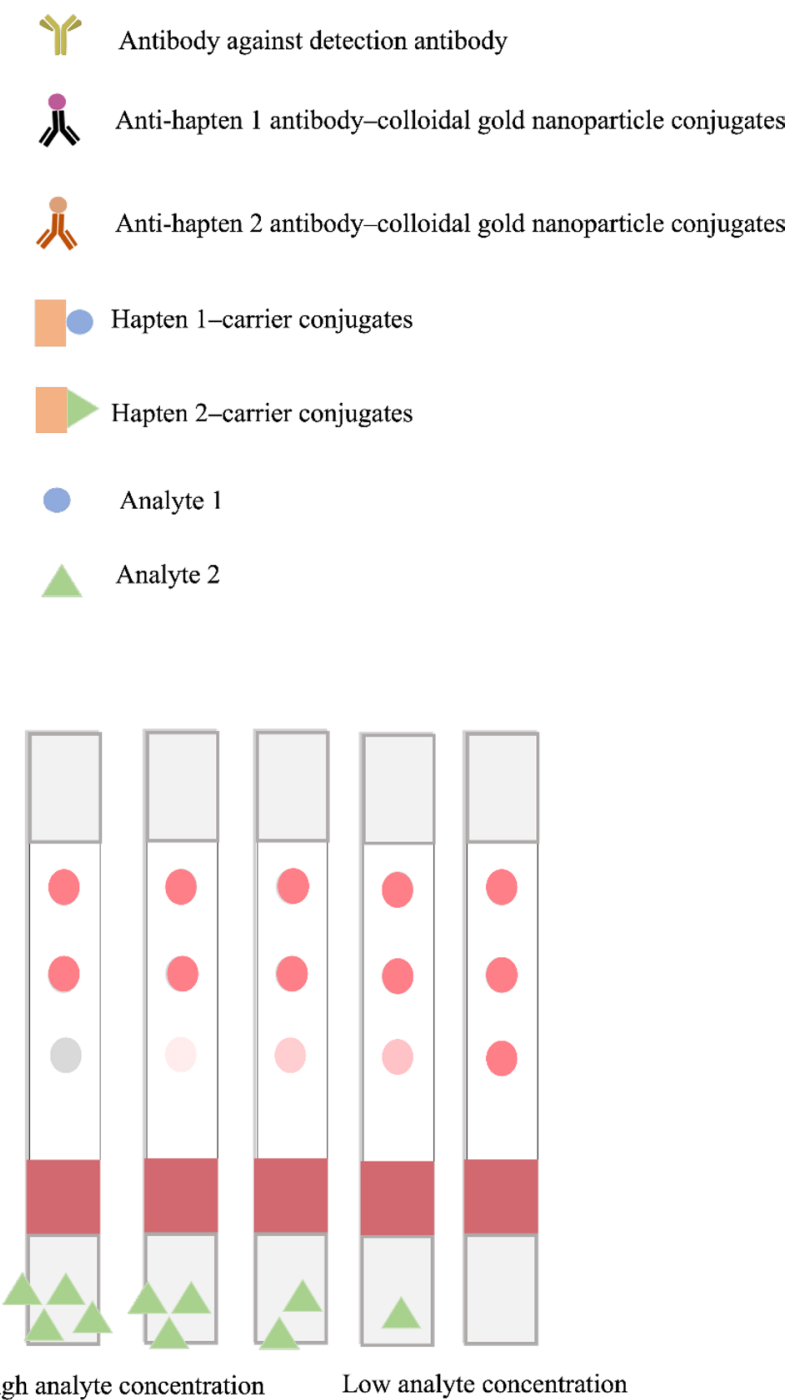

bolic representation of each compartment. The figure demonstrates the strip in various concentrations of analyte 1 and 2 
separated environment and applied in the same conjugate pads or test solution. In the general competitive format, there is only one test zone on the strip test, whereas the multiplex competitive format has more than one. The system incorporates the advantages from the multiple antibodies that render simultaneous detection possible in one analysis. The signal reporter elements can be the same (e.g., colloidal gold and colloidal gold) or different (e.g., colloidal gold and carbon nanoparticle) in one system. However, the selection of the nanoparticle for simultaneous detection presents many points of concern, particularly for compatibility among nanoparticles. The cross-reaction of the antibody is also a point of concern. The selected antibodies should not be bound to identical small compounds. This format can be extremely useful for controlling the quality of certain plants. The simultaneous detection system was first developed for the quality control of ginseng, in which the ginsenoside Rb1 and ginsenoside $\operatorname{Rg} 1$ (major biologically active compounds isolated from Panax ginseng) were used as analytes [51]. A sensitive detection system has been developed, regardless of the structural similarity between these analytes. According to the Japanese pharmacopoeia 18th edition (JP18th), the qualified Panax ginseng required the appropriate amount of ginsenoside $\mathrm{Rb} 1$ and ginsenoside $\mathrm{Rg} 1$ at $0.20 \%$ and $0.10 \%$ (w/w dry weight), respectively [52]. Therefore, the benefit of the strip test for screening the raw material is highlighted and fits the pharmacopoeia criteria. Nowadays, identical principles are used for several analytes, and this method is called microarray detection [53]. However, this concept has never been applied to phytoproducts.

\section{Sandwich format}

Apart from the competitive basis of immunochromatography, there is a sandwich immunochromatography format for small-molecule detection. Superior specificity is expected when the sandwich system is applied since the result appeared when two different antibodies recognized two different epitopes on the same antigen. The sandwich format of the LFA has generally been applied for a relatively large molecule, such as a microorganism cell [54] and protein [55]. This is because the sandwich system requires two distinct antibodies, which can bind to different epitopes. However, obtaining the appropriate pair of antibodies for secondary metabolites or an adulterant containing small molecules consumes several attempts and resources. This may be due to the steric hindrance blockage between the antigen-capture antibody and antigen-tag antibody [56]. In extremely small molecules, this format is practically impossible to develop because the epitope position was shorter than $5 \AA$ (the chain length of 5 carbon atoms), which was supposed to exhibit a minute chance of success [57]. However, a study has successfully performed the LFA using this format with modifications, as demonstrated in Fig. 4. The liquid flow of
Fig. 4 Sandwich format of the strip test. The upper section demonstrates the symbolic representation of each compartment. The figure demonstrates the LFA signal in various analyte concentrations. This figure was summarized from Teerinen et al. [58] where morphine was detected

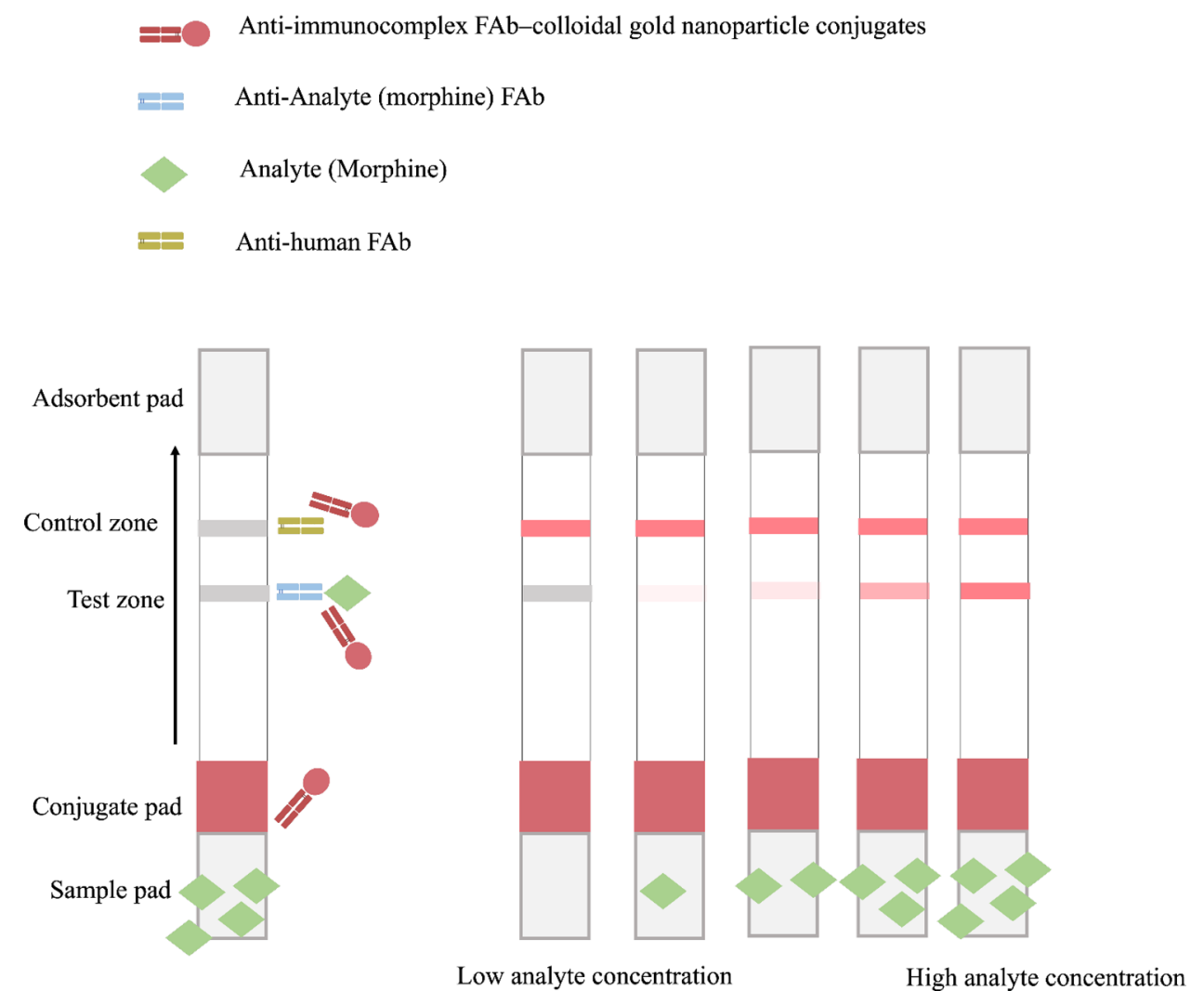


this format is identical to the competitive assay; however, the test zone was altered. The morphine-detectable LFA was developed by placing the anti-morphine fragmented antibody (FAb) on the test zone as a capture antibody [58]. When the morphine in the sample passed through the antimorphine FAb, the morphine molecule was bound to the anti-morphine FAb generating the immunocomplex (FAbmorphine complex). The reporter molecule (gold nanoparticle) that conjugated with the anti-immunocomplex FAb was used as a detection antibody. When the immunoprobe passed through the immunocomplex on the membrane, the reporter molecules were accumulated, and the visible band was shown on the strip. The higher the morphine content in a sample, the higher the intensity of the visible band obtained, which was the opposite read-out style, compared with that of the competitive format. Although the system is specific, sensitive, and easy to interpret, the format is not quite famous as it has not been applied for another natural compound or plant product adulterant, as far as we know. This may be due to the complex steps of dual antibody preparation and the time-consuming preparation of two antibodies.

\section{Type of analysis in LFA}

The LFA could be developed for qualitative, semi-quantitative, and quantitative analyses, up to the design of that individual study. Generally, LFA for phytoproducts is competitive format as mentioned in the previous section. Thus, type of analysis in LFA would discuss based on this format hereafter. Table 1 summarizes the detail of each type of analysis.

\section{Qualitative analysis}

This detects the presence or absence of the compound in the matrix; however, it cannot describe the concentration level of the compound. A positive result, absence of spot, in this assay type indicates that the analyte concentration is more than the limit of detection (LOD) of the system, whereas a negative result, presence of spot, indicates that the analyte concentration is lower than the LOD or that the compound is not present in the sample. Although the benefits of this analysis type are limited, most assays are developed for qualitative analysis because the result interpretation is simple and exhibits low variation among interpreters. Considering that the presence of spot is the result indicator, there is no requirement for special equipment or software for the interpretation. Moreover, the qualitative analysis is suitable for compound-rich and color-rich matrixes, such as plant extracts. Occasionally, the interference of the matrix leads to a malfunction of the antibody. Hence, defining the accurate amount of analyte is difficult because the intensity of the spot fluctuates from matrix to matrix. Additionally, the vivid or dark color of the extract could interfere with the results, when accurate intensity is required. However, the presence or absence of the spot can be easily justified.

\section{Semi-quantitative analysis}

This analysis provides the estimation of the concentration of an analyte in the form of levels. The results are usually categorized as the level of concentration of the analyte in a sample into high $(+++)$, medium $(++)$, low $(+)$, and very low/absence $(-)$ considering that the intensity of the spot is subjective. Thus, the intensity comparator is required to reduce the bias of the interpretation. To elucidate the interpretation, certain studies that applied the competitive format designated the absence of a spot as high concentration, a weak intensity spot as low concentration, and a strong intensity spot as an extremely low concentration or absence of analytes [34].

\section{Quantitative analysis}

Only few studies developed the LFA as a quantitative analysis tool because it requires more validation processes and special equipment for interpretation. The results obtained from this analysis are more detailed, and the exact amount of the analyte can be reported. The method validations to

Table 1 LFA analysis type

\begin{tabular}{llll}
\hline & Analysis type & & Quantitative \\
\cline { 2 - 4 } & Qualitative & Semi-quantitative & Strip reader \\
\hline Detection method & Visual observation & $\begin{array}{c}\text { Visual observation with comparison with } \\
\text { standard } \\
\text { Photo analysis software (optional) }\end{array}$ & $\begin{array}{c}\text { Scanner with photo analysis software } \\
\text { Results }\end{array}$ \\
Results interpretation & $\begin{array}{l}\text { Yes/no results } \\
\text { From presence/absence of } \\
\text { the spot }\end{array}$ & $\begin{array}{l}\text { From estimated intensity of the spot } \\
\text { Fight/concentration results }\end{array}$ & $\begin{array}{c}\text { From the intensity value which fits in } \\
\text { the determination curve }\end{array}$ \\
\hline
\end{tabular}


Table 2 Strengths and weaknesses of the LFA for phytoproducts analysis

\begin{tabular}{|c|c|}
\hline Strengths & Weaknesses \\
\hline Ready to use & High cost and high labor intensive for antibody production \\
\hline Rapid device preparation time & Non-specific binding of antibody possibly occurs \\
\hline Simple analytical procedure & Questioning reproducibility (especially lot-to-lot) \\
\hline Analyte-specific method & Yes/no results output \\
\hline $\begin{array}{l}\text { Shorter analytical time required compared to conventional chromatographic meth- } \\
\text { ods and ELISA }\end{array}$ & Comparator for semi-quantitative analysis is required \\
\hline No sample pretreatment step needed & The sensitivity is generally lower than ELISA \\
\hline \multicolumn{2}{|l|}{ Controlled storage condition is not required } \\
\hline \multicolumn{2}{|l|}{ Easy to scale-up } \\
\hline \multicolumn{2}{|l|}{ Cost-effective method } \\
\hline \multicolumn{2}{|l|}{ Easy to convert the signal to value } \\
\hline \multicolumn{2}{|l|}{ Applicable in many scenarios } \\
\hline \multicolumn{2}{|l|}{ No signal reader needed } \\
\hline \multicolumn{2}{|l|}{ No previous sample contamination } \\
\hline \multicolumn{2}{|l|}{ Low organic solvent requirement } \\
\hline Low sample volume needed & \\
\hline
\end{tabular}

obtain a reliable standard curve are required besides the qualitative analysis validation methods.

\section{Strengths and weaknesses of the LFA}

The strengths and weaknesses of the LFA are described in Table 2. The use of LFA for phytoproduct analysis provides various benefits over other detection methods. The main dominant point of the LFA is that it can be readily performed at the point of need because it is extremely portable. Most prepared strips require only an apply-andinterpret step. This reduces the need for skillful labor. The LFA generally requires a shorter time for one analysis when compared with the ELISA or conventional chromatographic methods. For certain systems, the liquid sample can be directly applied onto the strip without any sample pretreatment. Considering that the assay is based on the antibody and antigen reaction, a highly specific antibody can be used to obtain a highly analyte-specific assay. The already produced strip can be preserved and used when required under various conditions, even at room temperature [59]. The shelf life of the prepared strip is generally longer than that of the ELISA kit, which is usually prepared in liquid form. The strip can be easily scaled-up for a large batch production. The cost of all materials for one assay is reasonable. The signal can be simply interpreted by visual observation. Moreover, a signal reader is not required for the qualitative system. Thus, the reach ability of the assay is high, particularly in developing countries. The system is designed for single use. Thus, the possibility of contamination by a previous assay sample, which occurs in the conventional column chromatographic methods, is diminished. Moreover, the need for equipment sanitization is minimized. Compared with the conventional column chromatographic methods, this assay requires an extremely small amount of organic solvent, indicating that it is more environmentally friendly and safe for the user.

Although the LFA has various strengths, there are limitations. The specific antibody is the fundamental requirement of the assay, and the cost and labor for antibody production are relatively high. The nonspecific binding of the antibody occurs because of the cross-reaction profile of an antibody or by skipping the washing step in the LFA. The detection protocol generally does not involve washing the strip. The strip test is generally designed for "positive/negative" results. For the semi-quantitative and quantitative analyses, the intensity of the spot is difficult to achieve a subjective judgment. This limitation can be overcome with the use of a color intensity analytical software with input from membrane strip readers, scanners, or digital cameras. If a semi-quantitative analysis is required, the strips applied with gradient concentrations of the analyte are required for comparison. Dissimilar to the ELISA, this system generally has no signal amplifier, such as horseradish peroxidase. The system requires several molecules of the antibody-nanoparticle conjugates to provide a sufficient signal for reading. This results in lower sensitivity when compared with that of the ELISA.

\section{Production of anti-hapten antibody}

The unique structure glycoprotein called immunoglobulin (Ig) is the key component of the LFA as a detection tool. The antigen-specific antibody is secreted from the B-cell lymphocytes as a response of adaptive immune systems. 
The polyclonal antibody (pAb) and monoclonal antibody $(\mathrm{mAb})$ are applied in LFA. However, mAb is the major type of antibody used for phytoproducts analysis LFA because its specificity and sensitivity are selectable, and the batch-to-batch quality of the antibody is controllable
[60]. Regarding an avian-based antibody, the egg-derived polyclonal IgY antibody was applied in strip test fabrication [42]. The major isotype frequently applied in LFA is IgG because of its superior sensitivity, less cross-reactivity, and minimally complicated purification

(A)

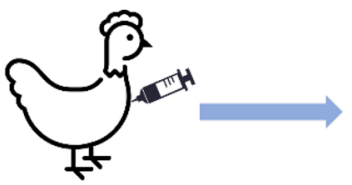

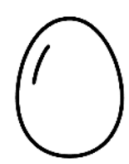

Egg-yolk collection

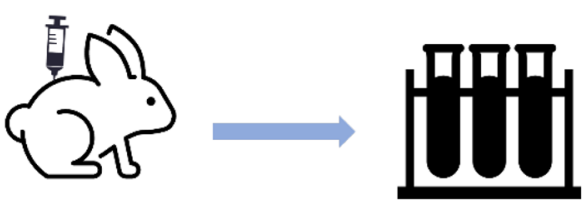

Animal immunization
Serum collection

(B)

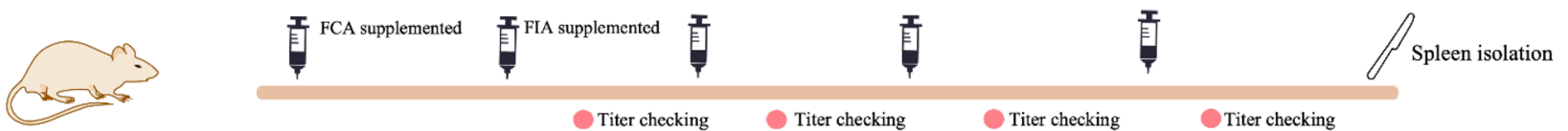

Immunized to the $\mathrm{BALB} / \mathrm{c}$ mice

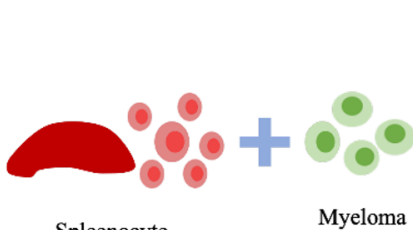

Spleenocyte

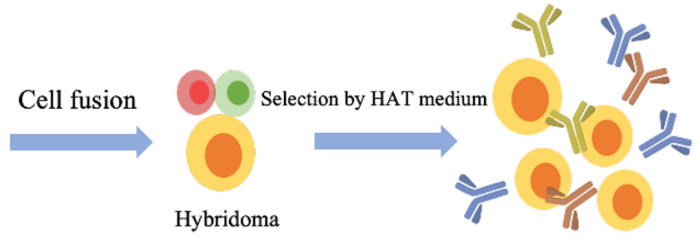

Hybridoma

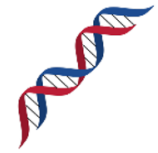

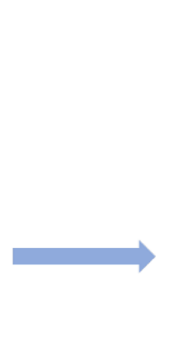

Hybridoma
Antibody encoding DNA

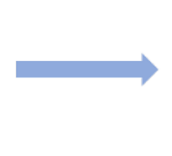

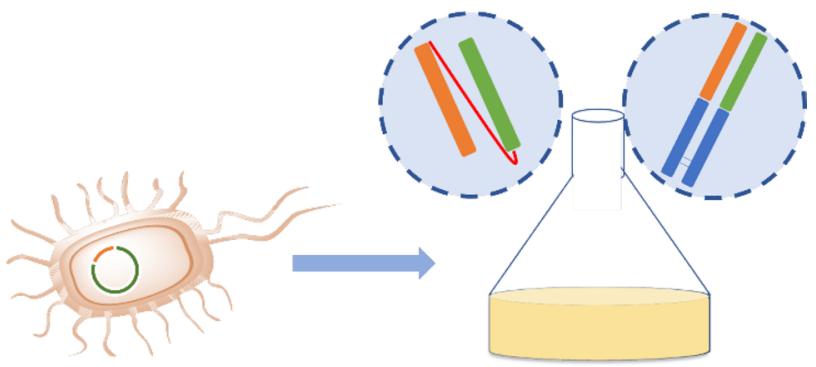

Clone into expression host
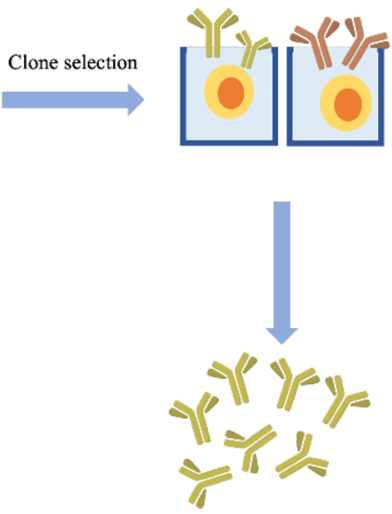

Monoclonal antibody (mAb)
Fig. 5 Summary of antibody production for the LFA applied for phytoproducts. A Production of pAb. In the avian host, polyclonal IgY is typically produced from the immunization of the avian; the egg yolk containing polyclonal IgY is collected and purified, and the serum containing polyclonal IgG is collected in the bigger animal, e.g., rabbit. B Production of $\mathrm{mAb}$ through the hybridoma technique. The animal host (mouse), as shown in the figure, was sequentially immunized, and the spleen was collected for cell fusion. The selection process using hypoxanthine-aminopterin-thymidine (HAT) medium and limited dilution enabled the desired characteristic hybridoma to be expanded. The mAb was produced from the supernatant of the selected clone. FCA and FIA represent Freund's complete adjuvant and Freund's incomplete adjuvant, respectively. C Production of recombinant antibody using bacteria as a host. The gene encoding the antibody was fragmented and cloned into the bacteria. With the appropriate expression technique, the fragmented antibody, i.e., FAb or single-chain variable fragment was produced 
process, compared with another isotype. Figure 5 shows the summary of antibody production for LFA applied for phytoproducts.

The antibody production of macromolecules $(\mathrm{Mw}>10,000 \mathrm{Da})$ is simple because the macromolecules frequently exhibit strong antigenicity. Plant secondary metabolites or contaminants are typically small-molecule compounds ( $\mathrm{Mw}<900 \mathrm{Da})$, which do not exhibit antigenicity. Therefore, various types of carriers have been used to enable these small molecules to exhibit antigenicity. Keyhole limpet hemocyanin (KLH) and BSA are the carriers of choice in the production of anti-small-molecule antibodies because these proteins possess many functional groups, which can be easily conjugated with small-molecule compounds using few steps [61, 62]. Moreover, these proteins are relatively large (KLH, $350 \mathrm{kDa}$; BSA, $66.5 \mathrm{kDa})$, compared with the small molecules. Thus, the immune system of the host animal can recognize, and the antibody can be successfully produced. The hybridoma formation is widely used when the production of $\mathrm{mAb}$ is required. There are three types of antibodies, which are predicted to be produced by the hybridoma, including the anti-carrier, anti-hapten-carrier complex, and anti-hapten antibodies. To sieve out the unwanted antibodies (anti-carrier and anti-hapten-carrier complex), the structurally different carrier conjugates, such as the human serum albumin (HSA), ovalbumin (OVA), mouse serum globulin, thyroglobulin, and diphtheria toxoid can be applied for antibody screening. The structurally different carrier conjugates can be used to develop the immunoassay when the antibody recognizes certain parts of the immunized molecules.

Recombinant antibody fragments are a group of antibodies that are not widely applied in the LFA because of their limited sensitivity and stability, compared with its parent antibody [63]. Moreover, the probability that the binding site of the antibody could bind to the detection probe was high because the molecules of these fragment antibodies were smaller. However, the ease of antibody production by Escherichia coli makes the recombinant antibody format attractive. Recently, a recombinant FAb was used as a single detection antibody to detect deoxymiroestrol, the potent phytoestrogen isolated from Pueraria candollei, in plant samples [64]. Noteworthily, the specificity and sensitivity profiles of this produced FAb were different from that of the original mAb [65]. The FAb tended to be more specific to one antigen rather than cross-reactive to structurally related compounds in this particular study. Therefore, the sensitive LFA of deoxymiroestrol was developed using these advantages.

\section{Reporter for LFA}

The labeling or reporter particle is the component that indicates the effectiveness and efficiency of the LFA. The antibody-directed particle accumulation generates a detectable signal on the membrane. There are various types of reporter particles applied in LFAs, such as colloidal gold nanoparticles, latex beads [66], carbon nanoparticles [67-69], composite nanoparticles [70], magnetic nanoparticles [71], liposomes [72], fluorescent probes [30, 42], and enzymes [73]. However, LFA for phytoproducts shared a common reporter molecule (colloidal gold nanoparticles), whereas a few used quantum dots or carbon nanoparticles as reporters. Table 3 lists the nanoparticles usually applied in LFAs for phytoproducts.

\section{Colloidal gold nanoparticles}

This is the fluid or suspension form of the gold usually suspended in a water-based solution. The scarlet suspension is typically preferred over the blue or purple suspension as the particle size is less than $100 \mathrm{~nm}$. The particle size of the nanoparticles can be selected according to the preference of the user. However, the oversize particles lead to the aggregation and sedimentation of the colloidal gold nanoparticles, whereas extremely small particles cause difficulty in the particle washing step and produce a meaningless color on the detection zones. The colloidal gold with a particle size exceeding $20 \mathrm{~nm}$ generated an interpretable signal [74]. Nevertheless, the appropriate particle size was proposed as approximately $40 \mathrm{~nm}$ because the maximum color was obtained at this size with the less steric hindrance of the antibody conjugation [74]. Colloidal gold is generally the first choice of material, owing to its various benefits. The labeling of the antibody to the colloidal gold can be performed by simple incubation. The antibody can bind to the colloidal gold particle through passive adsorption where the electrostatic force, hydrogen bonding, hydrophobicity, and Van der Waals forces are the main interactions [75, 76]. Moreover, the direction of the antibody (position of constant and variable regions) on the colloidal gold nanoparticles is manageable with surface modification [77]. Compared with other materials, the colloidal gold nanoparticles are relatively inexpensive. The particles are stable in solution or dried form. Additionally, the important characteristic of the colloidal gold nanoparticles is their long-lasting color on the membranes. The colloidal gold can be easily synthesized using various methods, and the surface functional group can be synthesized by preference $[78,79]$ and is easy to obtain through various commercial sources. When labeled with this nanoparticle, the assay results can be read-out on the basis of the colorimetric method. Nevertheless, the weaker signal intensity, compared with that of other nanoparticles is a 
Table 3 Nanoparticles used in LFA development applied for phytoproducts

\begin{tabular}{|c|c|c|c|c|}
\hline Nanoparticles & Color & Detection method & Strength & Weakness \\
\hline \multirow[t]{6}{*}{ Colloidal gold nanoparticles } & \multirow[t]{6}{*}{ Red-pink } & Visual observation & $\begin{array}{l}\text { Ease of labeling (physical } \\
\text { adsorption) }\end{array}$ & $\begin{array}{l}\text { Less color intensity lead to low } \\
\text { sensitivity }\end{array}$ \\
\hline & & $\begin{array}{l}\text { Strip reader (quantitative } \\
\text { analysis) }\end{array}$ & Manageable surface & $\begin{array}{l}\text { False positive and false negative } \\
\text { possibly occur }\end{array}$ \\
\hline & & $\begin{array}{l}\text { Photo analysis software } \\
\text { (optional) }\end{array}$ & Widely used & $\begin{array}{l}\text { Performance in red-yellow } \\
\text { colored samples is low }\end{array}$ \\
\hline & & & Commercially available & \\
\hline & & & $\begin{array}{l}\text { Ease of in-house synthesis and } \\
\text { functionalization }\end{array}$ & \\
\hline & & & $\begin{array}{l}\text { Stable in various LFA condi- } \\
\text { tion }\end{array}$ & \\
\hline \multirow[t]{7}{*}{ Quantum dots } & \multirow{7}{*}{$\begin{array}{l}\text { Depend on } \\
\text { the mate- } \\
\text { rial }\end{array}$} & Fluorescence strip reader & $\begin{array}{l}\text { Ease of labeling (chemical } \\
\text { conjugation) }\end{array}$ & Expensive \\
\hline & & $\begin{array}{l}\text { Visual observation (optional/ } \\
\text { lower sensitivity) }\end{array}$ & Low photo-bleaching & Fluorescent strip reader needed \\
\hline & & & $\begin{array}{l}\text { Stable in various LFA condi- } \\
\text { tion }\end{array}$ & Toxic to the environment \\
\hline & & & High sensitivity & \\
\hline & & & Wide range absorption spectra & \\
\hline & & & Specific emission wavelength & \\
\hline & & & Photostability & \\
\hline \multirow[t]{6}{*}{ Colloidal carbon } & \multirow[t]{6}{*}{ Black } & Visual observation & $\begin{array}{l}\text { Ease of labeling (physical } \\
\text { adsorption) }\end{array}$ & $\begin{array}{l}\text { Performance in black colored } \\
\text { samples is low }\end{array}$ \\
\hline & & $\begin{array}{l}\text { Photo analysis software } \\
\text { (optional) }\end{array}$ & Ease of In-house synthesis & \\
\hline & & & Cost-effective & \\
\hline & & & $\begin{array}{l}\text { Stable in various LFA condi- } \\
\text { tion }\end{array}$ & \\
\hline & & & Low toxicity & \\
\hline & & & $\begin{array}{l}\text { High contrast results (black and } \\
\text { white) }\end{array}$ & \\
\hline
\end{tabular}

point of concern. Generally, for the competitive immunoassay, the antibody concentration is important for the entire assay. The less the concentration of the antibody used in the system, the more sensitivity the developed system can be achieved. However, the colloidal gold nanoparticle-antibody conjugates concentration should be increased, when the signal is too weak to be interpreted. Moreover, false positives or negatives can occur in certain situations, such as environments with excess salt or extreme $\mathrm{pH}$. The given color on the zones of the strip is pinkish red. It is not suitable to apply these nanoparticles in a test, where the sample is colored in the same tone, such as anthocyanin-, carotenoid-, and flavonoid-rich samples. Figure 6A demonstrates an example of a signal obtained from these nanoparticles.

\section{Quantum dots}

These are semiconductor nanoparticles; their optoelectronic properties are dependent on their composition. Generally, the particle size of quantum dots is in a range of $1.5-10 \mathrm{~nm}$ [80]. They exhibit high colloidal stability. Moreover, the material has a low rate of photobleaching and high chemical stability. A few studies have used quantum dots to develop the LFA for phytoproducts $[37,42,81]$. This may be due to the high price of the materials. However, the high sensitivity assay was obtained as a trade-off for this drawback. Although the quantum dot-based LFA can provide a colorimetric read-out on the test zone, the visual observation is not usually used for final result analyses because of the sharp drop-off in the sensitivity. The fluorometric approach is typically used for such assay detections. Therefore, the user needs a specific strip reader to read the results. The antibody labeling can be easily conducted using simple carbodiimide-mediated methods or commercially recommended methods, depending on the functional group at the surface of the quantum dots and element of the antibody (Fv and Fc) preferred for conjugation. Compared with the organic dye labeling e.g., fluorescein and R-phycoerythrin, quantum dots 
(A)

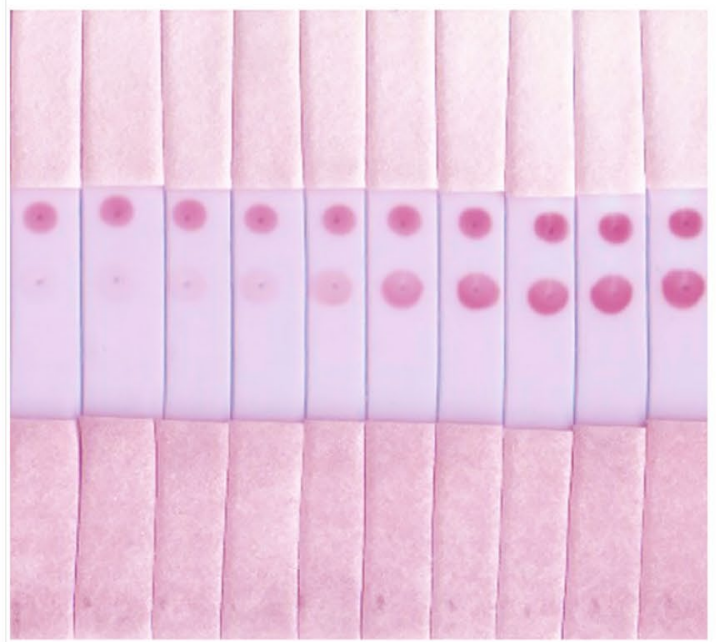

High analyte concentration
(B)

High analyte concentration Low analyte concentration
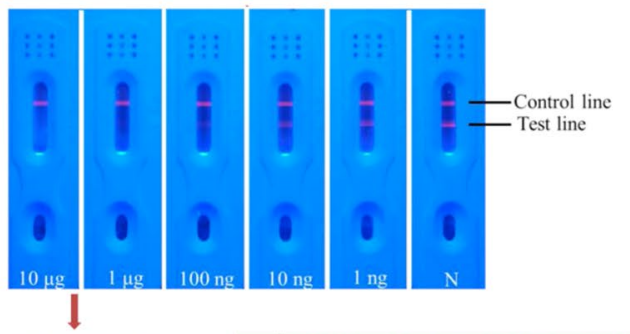

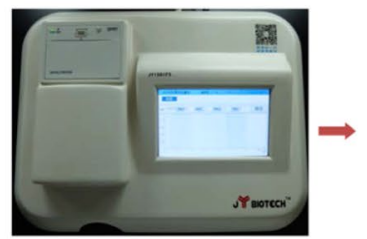

(C)

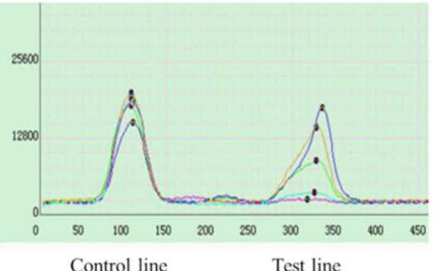

Low analyte concentration

High analyte concentration
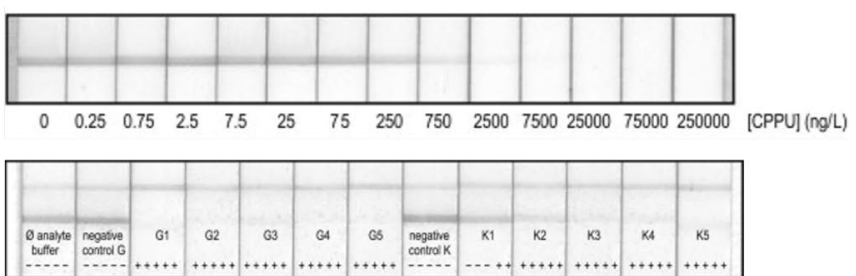

of the signal. The picture was adopted from Qu et al. [37]. C Signal obtained from the carbon nanoparticle. The upper section shows the signal of various analyte concentrations. The lower section is the real sample application of the lateral flow immunoassay. The picture was adopted from Suárez-Pantaleón et al. [88]

is usually used for read-out. The particles are easy to prepare for in-house use and are provided in various commercially available forms [83, 84]. There are a few forms applied in LFAs, such as nanostrings [67, 85] and nanotubes [86]. The carbon nanoparticles are extremely stable in various chromatographic environments. Moreover, their toxicity is relatively lower than that of quantum dots. The conjugation of the antibody to the probe is performed by simple incubation without any modification (physical adsorption) [67]. The results can be evaluated by visual observation because the black spot provides high contrast to the white color of the membrane [87]. These nanoparticles have been used in many fields for a decade. However, their application in plant sample detection is limited. Forchlorfenuron, the synthetic cytokinin usually spiked in agricultural products for regulating plant growth, was determined using carbon nanoparticles as an immunoprobe [88]. This LFA was developed to quantify the concentration of an analyte, which corresponded to the gray color measured using photo analysis software. The they are intense-colored particles, the colorimetric method 
limit of quantification was $89 \mathrm{ng} / \mathrm{L}$ in an optimized buffer and $33.4 \mathrm{mg} / \mathrm{kg}$ in a kiwi and grape matrix. Although the carbon nanoparticles possess versatile benefits, black compounds and black matrixes should not be used on the strip developed by these nanoparticles. Figure $6 \mathrm{C}$ demonstrates an example of a signal obtained from these nanoparticles.

\section{Production of hapten-carrier molecules}

Plant-derived compounds and contaminants are mostly small compounds. Small compounds are difficult to be immobilized to solid phase (well-plate and membrane) without pretreatment. Thus, hapten-carrier protein conjugates are generally used as an immobilizable antigen. There is no carrier of choice in LFAs for phytoproducts. The best carrier protein is selected on the basis of the experiment. The shape, size, and intensity of the band or spot in LFA per concentration unit are important factors. Small molecules can be conjugated with carriers with or without linkers. There are no solid rules in hapten-carrier design. Thus, an appropriate conjugation method for an individual hapten should be developed. Small molecules were routinely conjugated with carriers by simple chemical reactions (carbodiimide-mediated, sodium periodate, and Mannich reactions), as summarized in Table 4. The selection of these reactions depends on the structure of the target molecule. Considering that the reactive aldehyde is easily formed at the vicinal diol of the sugar part, which readily reacts with the amine group of the protein carrier, the sodium periodate reaction is typically preferred in the conjugation of sugar-containing compounds [37, 39, 42, 51, 89-94]. However, the cross-reaction of the antibody against the aglycone of the glycosides should be considered when the antigen is prepared by this reaction. The compounds with carboxylic acid and hydroxyl functional groups are usually conjugated by a carbodiimidemediated reaction [33, 34, 47, 95-102], whereas compounds with active hydrogen, e.g., $\alpha$-picolines, ketones, esters, and acetylenes, can be conjugated to an amine or amide group of the carrier by a Mannich reaction [103, 104]. Furthermore, structure modifications of the parent compounds to add the reactive functional group to the molecule can be conducted when necessary.
Table 4 Conjugation methods of the hapten-carrier protein used in LFA for phytoproducts

\begin{tabular}{|c|c|c|c|c|}
\hline Coupling method & Reagent & Analyte & Carrier & References \\
\hline \multirow{11}{*}{$\begin{array}{l}\text { Carbodiimide } \\
\text { mediated } \\
\text { method }\end{array}$} & CDI & Monocrotaline & HSA & {$[33]$} \\
\hline & CDI & Kwakhurin & BSA & {$[102]$} \\
\hline & CDI & $(S)$-Higenamine & Gamma globulin & {$[34]$} \\
\hline & CDI & Amarogentin & HSA & [46] \\
\hline & DCC & Glycyrrhizin & BSA & [97] \\
\hline & EDC & Sennosides A and B & HSA & [96] \\
\hline & EDC & Baicalin & BSA & [98] \\
\hline & $\mathrm{EDC}$ & Mitragynine & OVA & [99] \\
\hline & EDC & Salvinorin A & HSA & {$[100]$} \\
\hline & EDC & Mitragynine and 7-hydroxymitragynine & BSA & {$[101]$} \\
\hline & EDC & Aristolochic acid I & BSA & [47] \\
\hline \multirow[t]{2}{*}{ Mannich reaction } & Formaldehyde & Miroestrol & OVA & {$[103]$} \\
\hline & Formaldehyde & Isomiroestrol & Cationized OVA & {$[104]$} \\
\hline \multirow[t]{12}{*}{ Sodium periodate } & $\mathrm{NaIO}_{4}$ & Ginsenosides Rb1 and $\operatorname{Rg} 1$ & HSA & {$[51]$} \\
\hline & $\mathrm{NaIO}_{4}$ & Glycyrrhizin & HSA & [89] \\
\hline & $\mathrm{NaIO}_{4}$ & Pseudojujubogenin glycosides & HSA & {$[90]$} \\
\hline & $\mathrm{NaIO}_{4}$ & Asiaticoside & HSA & [91] \\
\hline & $\mathrm{NaIO}_{4}$ & Mulberroside A & OVA & [92] \\
\hline & $\mathrm{NaIO}_{4}$ & Puerarin & BSA & {$[37]$} \\
\hline & $\mathrm{NaIO}_{4}$ & Daidzin and genistin & HSA & [93] \\
\hline & $\mathrm{NaIO}_{4}$ & Harringtonine & BSA & {$[45]$} \\
\hline & $\mathrm{NaIO}_{4}$ & Miroestrol and puerarin & HSA & [94] \\
\hline & $\mathrm{NaIO}_{4}$ & Saikosaponin d & BSA & [39] \\
\hline & $\mathrm{NaIO}_{4}$ & Rhein & OVA & {$[42]$} \\
\hline & $\mathrm{NaIO}_{4}$ & Colchicine & OVA & [44] \\
\hline
\end{tabular}

$C D I$ carbonyldiimidazole, $D C C N, N^{\prime}$-dicyclohexylcarbodiimide, $E D C$ 1-ethyl-3-(3-dimethylaminopropyl) carbodiimide, $H S A$ human serum albumin, $B S A$ bovine serum albumin, $O V A$ albumin from egg white 
Table 5 Plant secondary metabolites which applied in LFA

\begin{tabular}{|c|c|c|c|}
\hline Secondary metabolites & Compounds classification & Plant resource & References \\
\hline Ginsenosides & Triterpenoid glycoside & Panax spp. & {$[51,106]$} \\
\hline Sennosides A and B & Hydroxyanthracene glycoside & Rhem spp., Senna spp. & [96] \\
\hline Glycyrrhizin & Triterpenoid glycoside & Glycyrrhiza spp. & {$[89,97]$} \\
\hline Pseudojujubogenin glycosides & Pseudojujubogenin glycoside & Bacopa monnieri & {$[90]$} \\
\hline Asiaticoside & Triterpenoid glycoside & Centella asiatica & [91] \\
\hline Baicalin & Flavone glycoside & Scutellaria baicalensis & [98] \\
\hline Morphine & Alkaloid & Papaver somuniferum & {$[58]$} \\
\hline Mulberroside A & Stilbene glucoside & Morus alba & {$[92]$} \\
\hline Puerarin & Isoflavone glycoside & Pueraria lobata & {$[37]$} \\
\hline Daidzin and genistin & Isoflavone glycoside & Glycine max & {$[93]$} \\
\hline Miroestrol & Chromene & Pueraria mirifica & {$[103]$} \\
\hline Harringtonine & Alkaloid & Cephalotaxus harringtonia & [45] \\
\hline Monocrotaline & Pyrrolizidine alkaloid & Crotalaria spp. & {$[33]$} \\
\hline Mitragynine & Indole alkaloid & Mitragyna speciosa & {$[99,101]$} \\
\hline Salvinorin A & Diterpenoid & Salvia divinorum & {$[100]$} \\
\hline Saikosaponin d & Triterpenoid glycoside & Bupleurum falcatum & [39] \\
\hline Icariin & Flavone glycoside & Epimedium spp. & {$[40]$} \\
\hline Isomiroestrol & Chromene & Pueraria mirifica & [104] \\
\hline Deoxymiroestrol & Chromene & Pueraria mirifica & {$[64]$} \\
\hline Triptolide & Diterpenoid epoxide & Tripterygium wilfordii & {$[38]$} \\
\hline Aristolochic acid I & Nitrophenanthrene & Aristolochia spp. & [47] \\
\hline Aconitine & Alkaloid & Aconitum spp. & [29] \\
\hline Rhein & Anthraquinone & Rheum officinale & {$[42]$} \\
\hline Kwakhurin & Isoflavonoids & Pueraria mirifica & [102] \\
\hline Higenamine & Benzyltetrahydroisoquinoline alkaloid & $\begin{array}{l}\text { Aconitum carmichaelii, Asarum heterotro- } \\
\text { phies, Nandina domestica }\end{array}$ & {$[34]$} \\
\hline Amarogentin & Secoiiridoid glycoside & Swertia spp., Gentiana spp. & [46] \\
\hline Colchicine & Alkaloid & Colchicum autumnale & {$[44]$} \\
\hline
\end{tabular}

\section{LFA developed to detect secondary metabolites in plant samples}

There are various important components in plants, such as proteins, polysaccharides, and small-molecule secondary metabolites. However, small-molecule secondary metabolites have gained attention because they were observed to be unique in particular plant species and had a high potential to be biologically active compounds. LFAs can be used on virtually all small-molecule secondary metabolites, such as triterpenoid glycoside, benzylisoquinoline alkaloid, and flavone glycoside, as listed in Table 5. The main purpose of developing the assay is to inspect the quality of plants by investigating the amount of biologically active and toxic compounds in the plants. The concept of small-molecule detection by LFA was first introduced in 1996 when the analyte was progesterone $(\mathrm{Mw}=314.46)$ [105]. The test zone was filled with an antiprogesterone antibody, and the detection probe was gold-labeled progesterone-OVA conjugates [105]. The strip functioned on a competitive basis, as mentioned in the "general principle of the LFA" section; however, the position of the main components (antibody and hapten-carrier protein conjugates) was switched. On the basis of this concept, the first LFA for ginsenosides Rb1 and Rg1 was invented [51]. Interestingly, no significant matrix effect that can alter the results was observed in this study, although the plant sample was extracted with an organic solvent and simply diluted before use. This advantage was observed in other studies and might be due to the affinity of the antibody to the antigen. Generally, the antibody can detect target compounds within the $\mathrm{ng} / \mathrm{mL}$ to $\mu \mathrm{g} / \mathrm{mL}$ level when it is applied to LFA. Therefore, it is not necessary to use a high-concentration sample. This ensures that the sample impurities that might interfere with the detection result (if any) are at a minimal level by simple dilution. Table 6 summarizes the plant secondary metabolite detection by the LFA. 


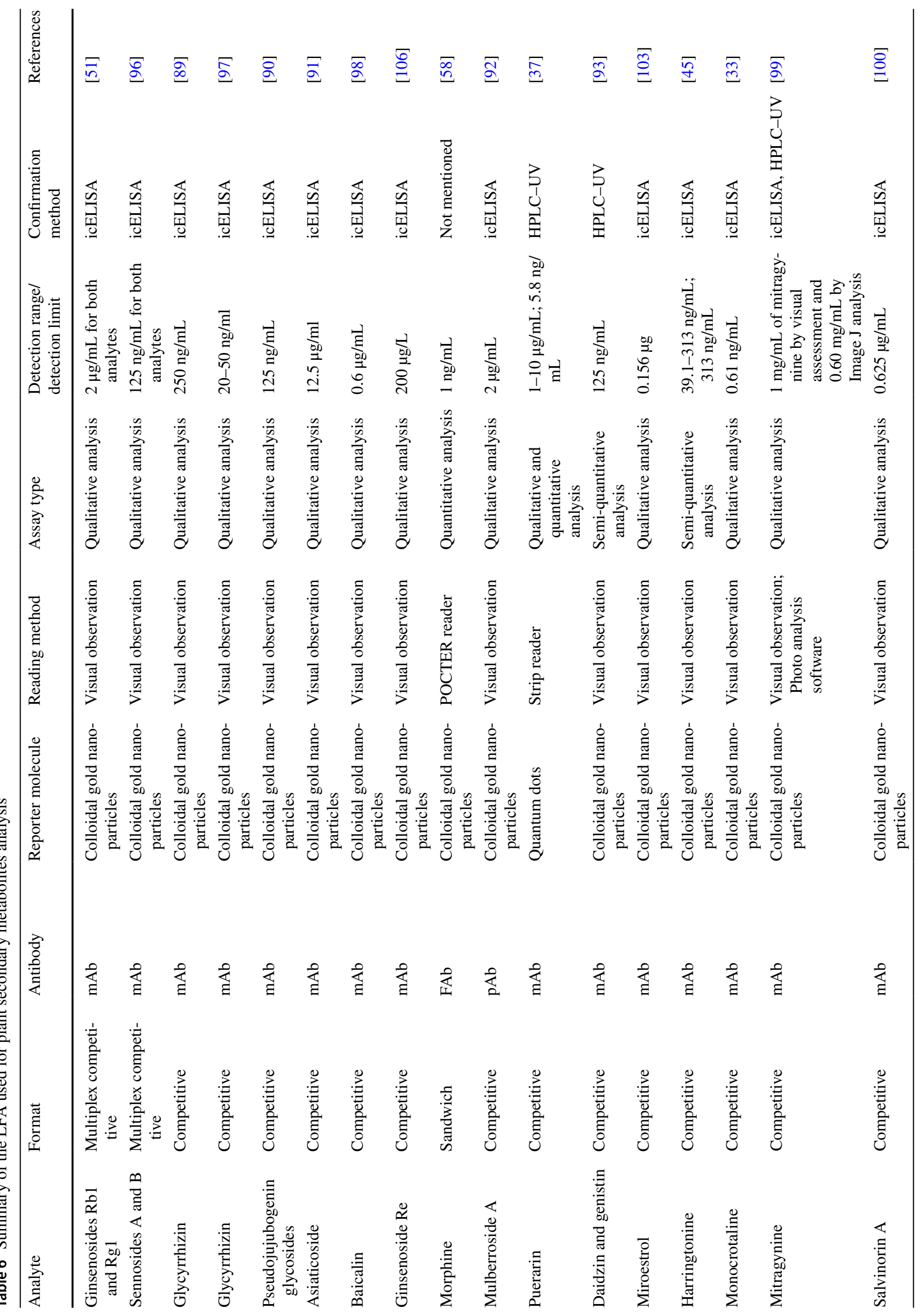




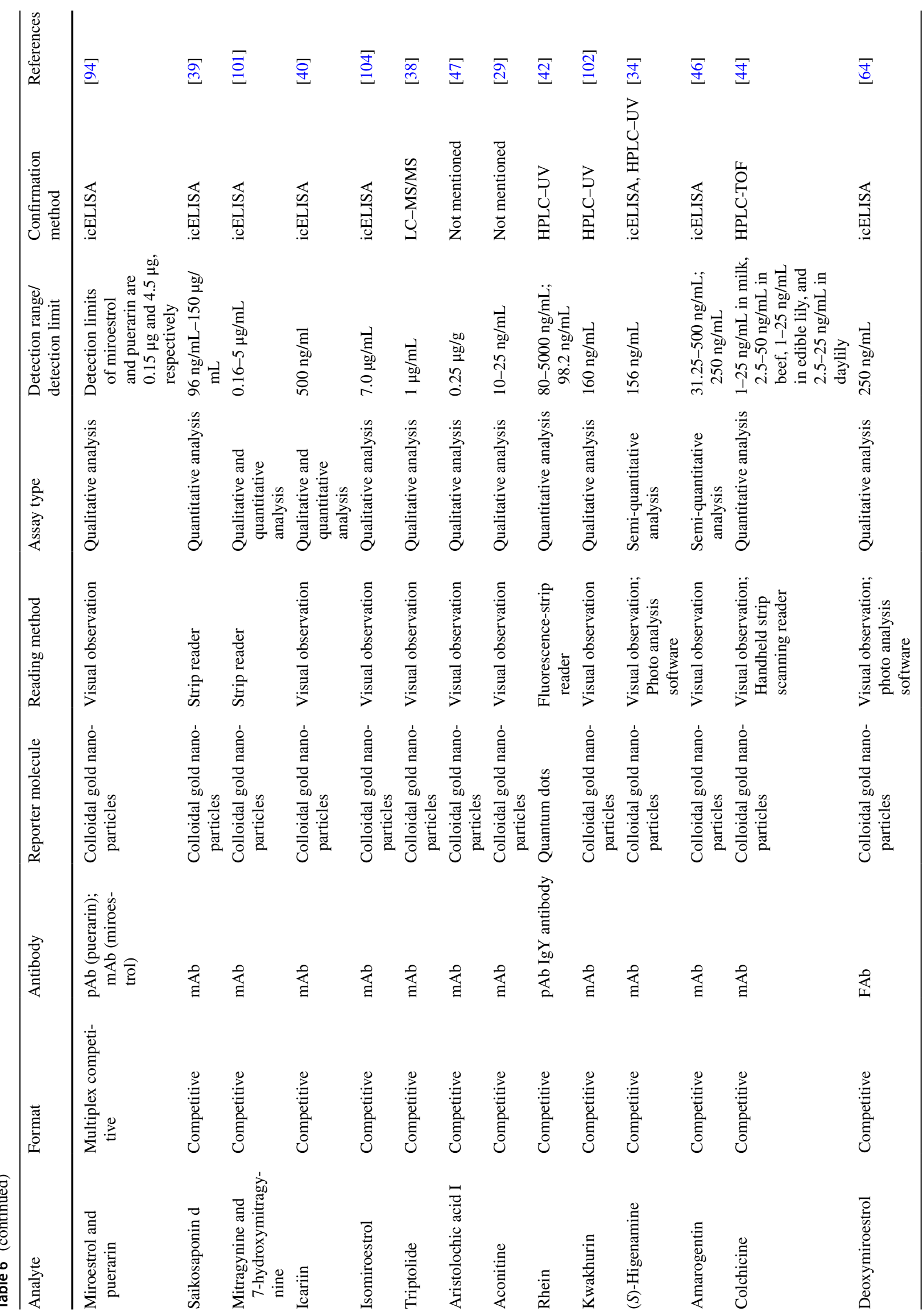


Table 7 Sensitivity comparison between LFA and icELISA

\begin{tabular}{|c|c|c|}
\hline Analyte & LFA determination range/LOD & icELISA determination range/LOD \\
\hline Ginsenosides $\mathrm{Rb} 1$ and $\operatorname{Rg} 1$ & $2 \mu \mathrm{g} / \mathrm{mL}$ for both analytes & $\begin{array}{l}\text { Ginsenoside } \mathrm{Rb} 1 \text { and } \mathrm{Rg} 1 \text { are } 20-400 \mathrm{ng} / \mathrm{mL} \text { [107] } \\
\text { and } 0.3-10 \mu \mathrm{g} / \mathrm{mL}[108] \text {, respectively }\end{array}$ \\
\hline Sennosides A and B & $125 \mathrm{ng} / \mathrm{mL}$ for both analytes & $\begin{array}{l}\text { Sennoside A and sennoside B are } 20-200 \mathrm{ng} / \mathrm{mL} \\
\text { [109] and } 0.5-15 \mathrm{ng} / \mathrm{mL}[110] \text {, respectively }\end{array}$ \\
\hline Glycyrrhizin & $250 \mathrm{ng} / \mathrm{mL}$ & $20-200 \mathrm{ng} / \mathrm{mL}[111]$ \\
\hline Glycyrrhizin & $20-50 \mathrm{ng} / \mathrm{ml}$ & $0.2-5.1 \mathrm{ng} / \mathrm{mL}[97]$ \\
\hline Pseudojujubogenin glycosides & $125 \mathrm{ng} / \mathrm{mL}$ & $1.95-62.5 \mathrm{ng} / \mathrm{mL} ; 0.5 \mathrm{ng} / \mathrm{mL}[112]$ \\
\hline Asiaticoside & $12.5 \mu \mathrm{g} / \mathrm{mL}$ & $0.78-50 \mu \mathrm{g} / \mathrm{mL} ; 6.2 \mu \mathrm{g} / \mathrm{mL}[113]$ \\
\hline Baicalin & $0.6 \mu \mathrm{g} / \mathrm{mL}$ & $200 \mathrm{ng} / \mathrm{mL}-2 \mu \mathrm{g} / \mathrm{mL} ; 100 \mathrm{ng} / \mathrm{mL}[114]$ \\
\hline Ginsenoside Re & $200 \mu \mathrm{g} / \mathrm{L}$ & $0.08-0.7 \mu \mathrm{g} / \mathrm{mL}[114]$ \\
\hline Morphine & $1 \mathrm{ng} / \mathrm{mL}$ & N/A \\
\hline Mulberroside A & $2 \mu \mathrm{g} / \mathrm{mL}$ & $0.17-15.62 \mu \mathrm{g} / \mathrm{mL}[115]$ \\
\hline Puerarin & $1-10 \mu \mathrm{g} / \mathrm{mL} ; 5.8 \mathrm{ng} / \mathrm{mL}$ & $10 \mathrm{ng} / \mathrm{mL}-1 \mu \mathrm{g} / \mathrm{mL} ; 181.3 \mathrm{ng} / \mathrm{mL}$ [37] \\
\hline Daidzin and genistin & $125 \mathrm{ng} / \mathrm{mL}$ & $1.95-62.5 \mathrm{ng} / \mathrm{mL} ; 1.95 \mathrm{ng} / \mathrm{mL}[116]$ \\
\hline Miroestrol & $0.156 \mu \mathrm{g}$ & $10-780 \mathrm{ng} / \mathrm{mL} ; 3.5 \mathrm{ng} / \mathrm{mL}[117]$ \\
\hline Harringtonine & $39.1-313 \mathrm{ng} / \mathrm{mL} ; 313 \mathrm{ng} / \mathrm{mL}$ & $0.76-48.8 \mathrm{ng} / \mathrm{mL} ; 0.76 \mathrm{ng} / \mathrm{mL}[118]$ \\
\hline Monocrotaline & $0.61 \mathrm{ng} / \mathrm{mL}$ & $48.8 \mathrm{pg} / \mathrm{mL}-3.13 \mathrm{ng} / \mathrm{mL}[119]$ \\
\hline Mitragynine & $\begin{array}{l}1 \mathrm{mg} / \mathrm{mL} \text { of mitragynine by visual assessment } \\
\text { and } 0.60 \mathrm{mg} / \mathrm{mL} \text { by Image } \mathrm{J} \text { analysis }\end{array}$ & $32.92-250 \mu \mathrm{g} / \mathrm{mL} ; 32.47 \mu \mathrm{g} / \mathrm{mL}[120]$ \\
\hline Salvinorin A & $0.625 \mu \mathrm{g} / \mathrm{mL}$ & $0.0195-0.625 \mu \mathrm{g} / \mathrm{mL} ; 0.0195 \mu \mathrm{g} / \mathrm{mL}[121]$ \\
\hline Miroestrol and puerarin & $\begin{array}{l}\text { Miroestrol and puerarin are } 0.15 \mu \mathrm{g} \text { and } 4.5 \mu \mathrm{g} \text {, } \\
\text { respectively }\end{array}$ & $\begin{array}{l}\text { Miroestrol and puerarin are } 10-780 \mathrm{ng} / \mathrm{mL} ; 3.5 \mathrm{ng} / \\
\mathrm{mL}[117] \text { and } 0.02-12.5 \mu \mathrm{g} / \mathrm{mL} ; 0.02 \mu \mathrm{g} / \mathrm{mL} \\
\text { [122], respectively }\end{array}$ \\
\hline Saikosaponin d & $96 \mathrm{ng} / \mathrm{mL}-150 \mu \mathrm{g} / \mathrm{mL}$ & 156.25 to $5000.00 \mathrm{ng} / \mathrm{mL} ; 148.41 \mathrm{ng} / \mathrm{mL}[123]$ \\
\hline Mitragynine and 7-hydroxymitragynine & $0.16-5 \mu \mathrm{g} / \mathrm{mL}$ & $0.047-6 \mu \mathrm{g} / \mathrm{mL}[101]$ \\
\hline Icariin & $500 \mathrm{ng} / \mathrm{mL}$ & $5-3125 \mathrm{ng} / \mathrm{mL} ; 8.41 \mathrm{ng} / \mathrm{mL}[40]$ \\
\hline Isomiroestrol & $7.0 \mu \mathrm{g} / \mathrm{mL}$ & $390-12,500 \mathrm{ng} / \mathrm{mL} ; 323 \mathrm{ng} / \mathrm{mL}[124]$ \\
\hline Triptolide & $1 \mu \mathrm{g} / \mathrm{mL}$ & N/A \\
\hline Aristolochic acid I & $0.25 \mu \mathrm{g} / \mathrm{g}$ & $\mathrm{IC}_{50}=5.02 \mathrm{ng} / \mathrm{mL}[47]$ \\
\hline Aconitine & $10-25 \mathrm{ng} / \mathrm{mL}$ & $1.13-11.76 \mathrm{ng} / \mathrm{mL}[29]$ \\
\hline Rhein & $80-5000 \mathrm{ng} / \mathrm{mL} ; 98.2 \mathrm{ng} / \mathrm{mL}$ & $5-3125 \mathrm{ng} / \mathrm{mL} ; 8.41 \mathrm{ng} / \mathrm{mL}[42]$ \\
\hline Kwakhurin & $160 \mathrm{ng} / \mathrm{mL}$ & $1.53-48.8 \mathrm{ng} / \mathrm{mL} ; 1.13 \mathrm{ng} / \mathrm{mL}[125]$ \\
\hline$(S)$-Higenamine & $156 \mathrm{ng} / \mathrm{mL}$ & $7.81-125 \mathrm{ng} / \mathrm{mL} ; 4.41 \mathrm{ng} / \mathrm{mL}[126]$ \\
\hline Amarogentin & $31.25-500 \mathrm{ng} / \mathrm{mL} ; 250 \mathrm{ng} / \mathrm{mL}$ & $1.95-62.5 \mathrm{ng} / \mathrm{mL} ; 1.28 \mathrm{ng} / \mathrm{mL}[95]$ \\
\hline Colchicine & $\begin{array}{l}1-25 \mathrm{ng} / \mathrm{mL} \text { in milk, } 2.5-50 \mathrm{ng} / \mathrm{mL} \text { in beef, } \\
1-25 \mathrm{ng} / \mathrm{mL} \text { in edible lily, and } 2.5-25 \mathrm{ng} / \mathrm{mL} \\
\text { in daylily }\end{array}$ & $0.09-2.16 \mathrm{ng} / \mathrm{mL}[44]$ \\
\hline Deoxymiroestrol & $250 \mathrm{ng} / \mathrm{mL}$ & $31.25-1,000 \mathrm{ng} / \mathrm{mL} ; 30.80 \mathrm{ng} / \mathrm{mL}[127]$ \\
\hline
\end{tabular}

\section{Selectivity of the system}

The selectivity of the LFA is an important factor that validates LFA results. The benefit of an antibody-based assay over the chromatographic-based assay is the selectivity. The molecular-level structure recognition of the antibody-antigen reaction is theoretically more selective than the conventional detectors, such as UV-Vis or fluorescent detectors. However, the cross-reactivity of the antibody against small molecules should be investigated. Considering that the matrix of the sample is usually the organic solvent extract of the plant of interest, there is a high chance that structurally similar compounds originating from the mutual biosynthesis pathway are present in the matrix. Furthermore, the glucoside form (aglycone target) or aglycone form (glycoside target) of the target compounds should be considered. The antibody that exhibits the cross-reaction might be useful when the cross-reacted compound is not present in the plant [34]. In certain cases, the broad cross-reaction of the antibody is useful when the class detection or total amount of 


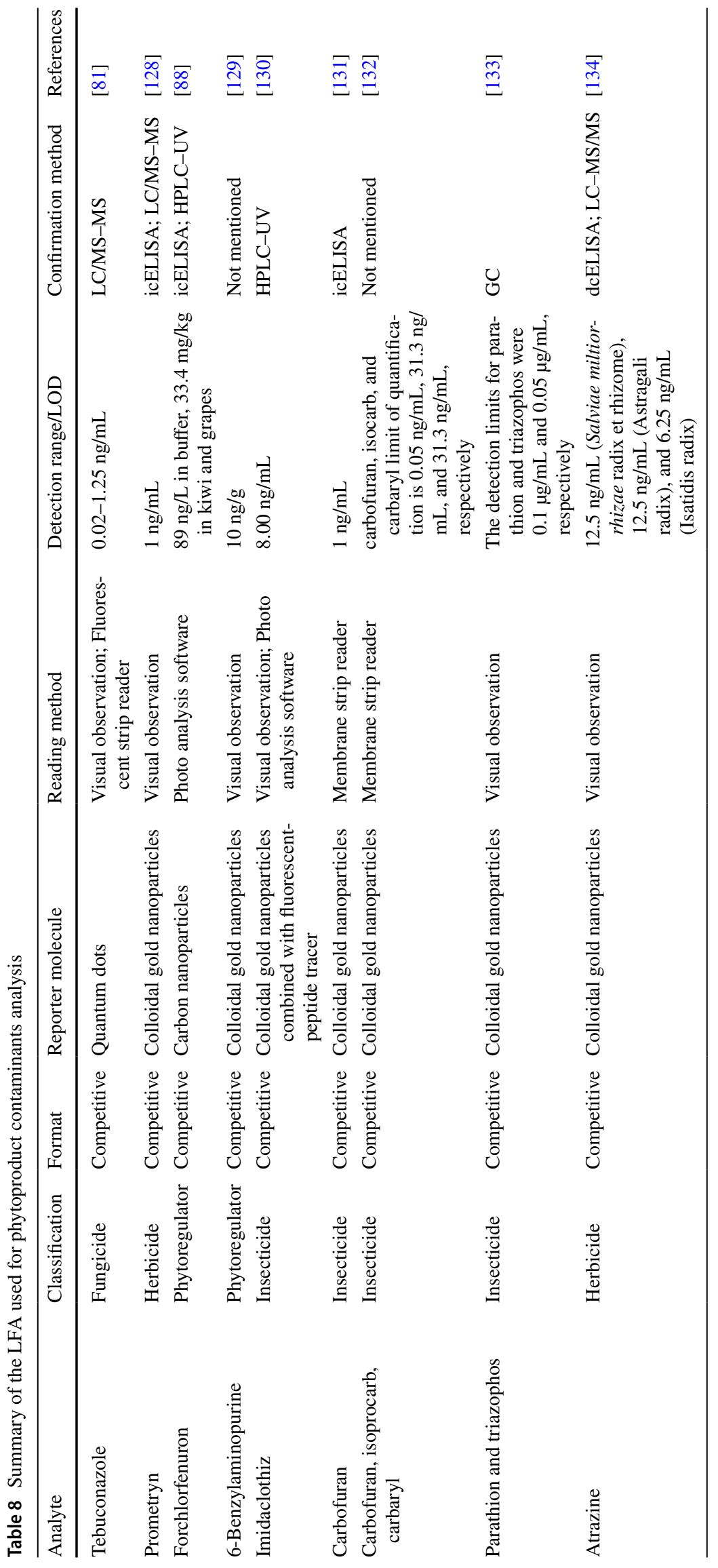


the analyte and its cross-reacted compounds is desired [93]. Most antibodies applied in the LFA are well-characterized using icELISA before use. However, the cross-reactivity of the LFA system has been revised to ensure selectivity after conjugation with reporter molecules. Interestingly, the cross-reaction profiles obtained from LFAs correlate with the icELISA result in most LFAs applied for plant samples. This indicates that the cross-reaction profile of the antibodies is usually not altered by nanoparticle conjugation at least in LFAs applied for plant samples. The cross-reaction test is simply performed by challenging the developed LFA with cross-reaction compound candidates at a certain concentration. In certain cases, the percentage of cross-reaction (\%CR) can be reported using the relative proportion of the LOD of the target compound and that of the candidates [33].

Additionally, the selection of the antibody type is important. Both pAb and mAb are applied in LFA. Similar to other antibody-based assays, $\mathrm{pAb}$, which normally recognizes multiple epitopes, theoretically exhibit lower selectivity compared with $\mathrm{mAb}$, which recognizes a single epitope and desired characteristics are precisely refined [13]. Hence, the antibody of choice for LFA is the mAb. Nevertheless, there are exceptions in certain haptens. For puerarin, pAb [94], and $\mathrm{mAb}$ [37] were applied in LFA and exhibited similar cross-reactivity profiles.

\section{Sensitivity of the system}

For LFA, the sensitivity indicates the usefulness of the system. Generally, the strip test is suitable for screening purposes. Hence, the sensitivity does not need to be as high as the confirmation analysis. However, optimization to obtain the highest sensitivity is recommended. The sensitivity of the LFA applied for plant samples is usually described as the LOD of the developed system. As mentioned in Table 7, the LOD of the LFA is usually higher than that of the ELISAbased method. Nevertheless, the sensitivity remains comparable or superior to the conventional chromatographic method in a few cases.

\section{LFA developed to detect the chemical contaminants}

The presence of unnatural contaminants in plants is a point of concern for consumers. There are various compounds spiked into crops for agricultural purposes. Herbicides and insecticides are used in the large-scale production of plants to control weeds and pests, thereby preserving the yield. Occasionally, the use of fungicides is necessary to combat fungal microorganisms to preserve the yield, shelf life, and quality of plants [12]. Phytoregulators are necessary for controlling the growth rate and growth stages (flowering and fruiting) of crops. Although these chemicals are necessary for agricultural purposes, the high intake of these chemicals can be harmful to consumers. Thus, a limited level of these compounds is set to ensure safe consumption. Several studies have attempted to promptly detect chemical contaminants in phytoproducts, as summarized in Table 8 . Samples containing contaminants can be extracted by simple organic solvent extraction. The detection method is based on the competitive format. Noteworthily, the major developed strip tests for chemical contaminants are highly sensitive (several $\mathrm{ng} / \mathrm{mL}$ for LOD) to meet the limit of contaminants in plant samples.

\section{Conclusion}

Phytoproducts are important for various industries. The small molecules in these products were highlighted because they are a quality indicator for phytoproducts. Reliable methods for controlling plant quality through qualitative and quantitative analyses of plant secondary metabolites and contaminants have been developed. Herein, LFA was discussed in the perspective of components, fabrication, and formats that apply in a complex matrix, such as a plant sample. Although the sensitivity of the LFA method is incomparable with that of the ELISA-based method or newgeneration chromatographic methods, it is a representative analytical method suitable for the rapid screening of plant samples. The cost-effectiveness, selectivity, and simplicity of this method are exceptional. However, the main developmental obstacle is the specific antibody production for a particular antigen because the selectivity cannot be improved once a system is developed. There is room for studies to investigate sensitivity using the enzyme-based LFA or fluorescent probe, as this could cause a big leap in improvement. Furthermore, the scarcity of colloidal gold nanoparticles during the pandemic could lead to a stock shortage. The invention of ecofriendly alternative nanoparticles that exhibit identical or superior sensitivity is challenging. Thus, studies on LFAs for phytoproduct analysis remain evergreen.

Open Access This article is licensed under a Creative Commons Attribution 4.0 International License, which permits use, sharing, adaptation, distribution and reproduction in any medium or format, as long as you give appropriate credit to the original author(s) and the source, provide a link to the Creative Commons licence, and indicate if changes were made. The images or other third party material in this article are included in the article's Creative Commons licence, unless indicated otherwise in a credit line to the material. If material is not included in the article's Creative Commons licence and your intended use is not permitted by statutory regulation or exceeds the permitted use, you will need to obtain permission directly from the copyright holder. To view a copy of this licence, visit http://creativecommons.org/licenses/by/4.0/. 


\section{References}

1. Tiwari R, Rana CS (2015) Plant secondary metabolites: a review. Int J Eng Res Gen Sci 3:661-670

2. Chiocchio I, Mandrone M, Tomasi P, Marincich L, Poli F (2021) Plant secondary metabolites: an opportunity for circular economy. Molecules 26:495

3. Fürstenberg-Hägg J, Zagrobelny M, Bak S (2013) Plant defense against insect herbivores. Int J Mol Sci 14:10242-10297

4. Bennett RN, Wallsgrove RM (1994) Secondary metabolites in plant defence mechanisms. New Phytol 127:617-633. https:// doi.org/10.1111/j.1469-8137.1994.tb02968.x

5. Demain AL, Fang A (2000) The natural functions of secondary metabolites. Adv Biochem Eng Biotechnol 69:1-39

6. Liu C, Cheng Y, Guo D, Zhang T, Li Y, Hou W, Huang L, Xu $\mathrm{H}$ (2017) A new concept on quality marker for quality assessment and process control of Chinese medicines. Chin Herb Med 9:3-13. https://doi.org/10.1016/s1674-6384(17)60070-4

7. World Health Organization (2009) Forty-third report of the WHO expert committee on specifications for pharmaceutical formulations

8. Ernst E (2002) Toxic heavy metals and undeclared drugs in Asian herbal medicines. Trends Pharmacol Sci 23:136-139

9. Ching CK, Lam YH, Chan AYW, Mak TWL (2012) Adulteration of herbal antidiabetic products with undeclared pharmaceuticals: a case series in Hong Kong. Br J Clin Pharmacol 73:795-800. https://doi.org/10.1111/j.1365-2125.2011.04135.x

10. Ching CK, Chen SPL, Lee HHC, Lam YH, Ng SW, Chen ML, Tang MHY, Chan SSS, Ng CWY, Cheung JWL, Chan TYC, Lau NKC, Chong YK, Mak TWL (2018) Adulteration of proprietary Chinese medicines and health products with undeclared drugs: experience of a tertiary toxicology laboratory in Hong Kong. Br J Clin Pharmacol 84:172-178. https://doi.org/ $10.1111 /$ bcp. 13420

11. Ernst E (2002) Adulteration of Chinese herbal medicines with synthetic drugs: a systematic review. J Intern Med 252:107-113

12. Zubrod JP, Bundschuh M, Arts G, Brühl CA, Imfeld G, Knäbel A, Payraudeau S, Rasmussen JJ, Rohr J, Scharmüller A, Smalling K, Stehle S, Schulz R, Schäfer RB (2019) Fungicides: an overlooked pesticide class? Environ Sci Technol 53:3347-3365. https://doi.org/10.1021/acs.est.8b04392

13. Sakamoto S, Putalun W, Vimolmangkang S, Phoolcharoen W, Shoyama Y, Tanaka H, Morimoto S (2018) Enzyme-linked immunosorbent assay for the quantitative/qualitative analysis of plant secondary metabolites. J Nat Med 72:32-42

14. Singer JM, Plotz CM (1956) The latex fixation test: I. Application to the serologic diagnosis of rheumatoid arthritis. Am J Med 21:888-892. https://doi.org/10.1016/0002-9343(56)90103-6

15. Yalow RS, Berson SA (1960) Immunoassay of endogenous plasma insulin in man. J Clin Invest 39:1157-1175. https://doi. org/10.1172/JCI104130

16. Avrameas S (1969) Coupling of enzymes to proteins with glutaraldehyde. Use of the conjugates for the detection of antigens and antibodies. Immunochemistry 6:43-48. https://doi.org/10.1016/ 0019-2791(69)90177-3

17. Leuvering JHW, Thai PJHM, Van der Waart MV, Schuurs AHWM (1980) Sol particle immunoassay (spia). J Immunoassay 1:77-91. https://doi.org/10.1080/01971528008055777

18. O'Farrell B (2009) Evolution in lateral flow-based immunoassay systems. In: Lateral flow immunoassay, pp 1-33

19. Chen Y, Wang Y, Xiao M, Wei S, Yang H, Yin R (2021) Polymerase chain reaction with lateral flow sensor assay for the identification of horse meat in raw and processed meat products. Food Chem. https://doi.org/10.1016/j.foodchem.2020.128840
20. Velasco A, Ramilo-Fernández G, Denis F, Oliveira L, Shum P, Silva H, Sotelo CG (2021) A new rapid method for the authentication of common octopus (Octopus vulgaris) in seafood products using recombinase polymerase amplification (rpa) and lateral flow assay (lfa). Foods 10:1825

21. Banger S, Pal V, Tripathi NK, Goel AK (2021) Development of a PCR lateral flow assay for rapid detection of Bacillus anthracis, the causative agent of anthrax. Mol Biotechnol 63:702-709. https://doi.org/10.1007/s12033-021-00335-6

22. Jauset-Rubio M, Svobodová M, Mairal T, McNeil C, Keegan N, Saeed A, Abbas MN, El-Shahawi MS, Bashammakh AS, Alyoubi AO, O'Sullivan CK (2016) Ultrasensitive, rapid and inexpensive detection of DNA using paper based lateral flow assay. Sci Rep 6:37732. https://doi.org/10.1038/srep37732

23. Kettler H, White K, Hawkes S (2004) Mapping the landscape of diagnostics for sexually transmitted infections: key findings and recommandations. Unicef/Undp/World Bank/Who 1-44

24. Land KJ, Boeras DI, Chen XS, Ramsay AR, Peeling RW (2019) REASSURED diagnostics to inform disease control strategies, strengthen health systems and improve patient outcomes. Nat Microbiol 4:46-54

25. Serrano MM, Rodríguez DN, Palop NT, Arenas RO, Córdoba MM, Mochón MDO, Cardona CG (2020) Comparison of commercial lateral flow immunoassays and ELISA for SARS-CoV-2 antibody detection. J Clin Virol 129:104529. https://doi.org/10. 1016/j.jcv.2020.104529

26. Courtney RC, Taylor SL, Baumert JL (2016) Evaluation of commercial milk-specific lateral flow devices. J Food Prot 79:17671774. https://doi.org/10.4315/0362-028X.JFP-16-127

27. Myers MJ, Yancy HF, Farrell DE, Washington JD, Frobish RA (2005) Evaluation of two commercial lateral-flow test kits for detection of animal proteins in animal feed. J Food Prot 68:26562664. https://doi.org/10.4315/0362-028X-68.12.2656

28. Li Y, Xie H, Wang J, Li X, Xiao Z, Xu Z, Lei H, Shen X (2021) Lateral flow immunochromatography assay for detection of furosemide in slimming health foods. Foods 10:2041. https://doi.org/ 10.3390/foods 10092041

29. Li S, Wu X, Kuang H, Liu L (2020) Development of an ic-ELISA and an immunochromatographic strip assay for the detection of aconitine. Food Agric Immunol 31:243-254. https://doi.org/10. 1080/09540105.2020.1714555

30. Ryu JH, Kwon M, Moon JD, Hwang MW, Lee JM, Park KH, Yun SJ, Bae HJ, Choi A, Lee H, Jung B, Jeong J, Han K, Kim Y, Oh EJ (2018) Development of a rapid automated fluorescent lateral flow immunoassay to detect Hepatitis B surface antigen (HBsAg), antibody to HBsAg, and antibody to Hepatitis C. Ann Lab Med 38:578-584. https://doi.org/10.3343/alm.2018.38.6.578

31. Alam N, Tong L, He Z, Tang R, Ahsan L, Ni Y (2021) Improving the sensitivity of cellulose fiber-based lateral flow assay by incorporating a water-dissolvable polyvinyl alcohol dam. Cellulose 28:8641-8651. https://doi.org/10.1007/s10570-021-04083-3

32. Tsai TT, Huang TH, Chen CA, Ho NYJ, Chou YJ, Chen CF (2018) Development a stacking pad design for enhancing the sensitivity of lateral flow immunoassay. Sci Rep 8:17319. https:// doi.org/10.1038/s41598-018-35694-9

33. Yusakul G, Sakamoto S, Chanpokapaiboon K, Tanaka H, Morimoto S (2019) Preincubation format for a sensitive immunochromatographic assay for monocrotaline, a toxic pyrrolizidine alkaloid. Phytochem Anal 30:653-660. https://doi.org/10.1002/ pca. 2838

34. Nuntawong P, Ochi A, Chaingam J, Tanaka H, Sakamoto S, Morimoto S (2021) The colloidal gold nanoparticle-based lateral flow immunoassay for fast and simple detection of plant-derived doping agent, higenamine. Drug Test Anal 13:762-769. https:// doi.org/10.1002/dta.2981 
35. Mansfield MA (2007) The use of nitrocellulose membranes in lateral-flow assays. In: Drugs of abuse, pp 71-85

36. Zeng Y, Liang D, Zheng P, Zhang Y, Wang Z, Mari GM, Jiang $\mathrm{H}$ (2021) A simple and rapid immunochromatography test based on readily available filter paper modified with chitosan to screen for 13 sulfonamides in milk. J Dairy Sci 104:126-133. https:// doi.org/10.3168/jds.2020-18987

37. Qu H, Zhang Y, Qu B, Kong H, Qin G, Liu S, Cheng J, Wang Q, Zhao Y (2016) Rapid lateral-flow immunoassay for the quantum dot-based detection of puerarin. Biosens Bioelectron 81:358362. https://doi.org/10.1016/j.bios.2016.03.008

38. Duan Y, Luo J, Liu C, Shan L, Dou X, Yang S, Yang M (2019) Rapid identification of triptolide in Tripterygium wilfordii products by gold immunochromatographic assay. J Pharm Biomed Anal 168:102-112. https://doi.org/10.1016/j.jpba.2019.02.020

39. Zhang Y, Xiao W, Kong H, Cheng J, Yan X, Zhang M, Wang Q, Qu H, Zhao Y (2018) A highly sensitive immunochromatographic strip test for rapid and quantitative detection of saikosaponin d. Molecules 23:338. https://doi.org/10.3390/molecules2 3020338

40. Qu H, Qu B, Cheng J, Zhang Y, Zeng W, Wang Q, Kong H, Zhao Y (2018) Development of a one-step lateral flow immunoassay for rapid detection of icariin. Curr Pharm Anal 14:101-107. https://doi.org/10.2174/1573412913666161214125948

41. Zhang B, Nan TG, Xin J, Zhan ZL, Kang LP, Yuan Y, Wang BM, Huang LQ (2019) Development of a colloidal gold-based lateral flow dipstick immunoassay for rapid detection of chlorogenic acid and luteoloside in Flos Lonicerae Japonicae. J Pharm Biomed Anal 170:83-88. https://doi.org/10.1016/j.jpba.2019.03. 035

42. Zhang Y, Kong H, Liu X, Cheng J, Zhang M, Wang Y, Lu F, Qu H, Zhao Y (2018) Quantum dot-based lateral-flow immunoassay for rapid detection of rhein using specific egg yolk antibodies. Artif Cells Nanomed Biotechnol 46:1685-1693. https://doi.org/10.1080/21691401.2017.1389749

43. Li S, Zhu J, Ma W, Kuang H, Liu L, Xu C (2021) Development of a lateral-flow ICA strip for the detection of colchicine. Anal Methods 13:3092-3100. https://doi.org/10.1039/d1ay00804h

44. Lee D, Ozkaya-Ahmadov T, Chu CH, Boya M, Liu R, Fatih Sarioglu A (2021) Capillary flow control in lateral flow assays via delaminating timers. Sci Adv. https://doi.org/10.1126/sciadv.abf9833

45. Sakamoto S, Yusakul G, Nuntawong P, Kitisripanya T, Putalun W, Miyamoto T, Tanaka H, Morimoto S (2017) Development of an indirect competitive immunochromatographic strip test for rapid detection and determination of anticancer drug, harringtonine. J Chromatogr B Anal Technol Biomed Life Sci 1048:150-154. https://doi.org/10.1016/j.jchromb.2017.01.032

46. Nuntawong P, Lohseethong K, Juengwatanatrakul T, Yusakul G, Putalun W, Tanaka H, Sakamoto S, Morimoto S (2021) Competitive immunochromatographic test strips for the rapid semi-quantitative analysis of the biologically active bitter glycoside, amarogentin. J Immunoass Immunochem 42:48-61. https://doi.org/10.1080/15321819.2020.1819308

47. Li S, Wu X, Song S, Zheng Q, Kuang H (2019) Development of ic-ELISA and an immunochromatographic strip assay for the detection of aristolochic acid I. Food Agric Immunol 30:140 149. https://doi.org/10.1080/09540105.2018.1551331

48. Han W, Shin JH (2021) Low-cost, open-source 3D printed antibody dispenser for development and small-scale production of lateral flow assay strips. HardwareX. https://doi.org/10.1016/j. ohx.2021.e00188

49. Choi S, Lee JH, Choi JS, Il JH (2015) Economical and rapid manufacturing of lateral flow immunosensor using fountain pens and gold colloidal solution. Anal Methods 7:1834-1842. https://doi.org/10.1039/c4ay02940b
50. Credou J, Faddoul R, Berthelot T (2015) Photo-assisted inkjet printing of antibodies onto cellulose for the eco2-friendly preparation of immunoassay membranes. RSC Adv 5:2978629798. https://doi.org/10.1039/c5ra03442f

51. Putalun W, Fukuda N, Tanaka H, Shoyama Y (2004) A onestep immunochromatographic assay for detecting ginsenosides $\mathrm{Rb} 1$ and $\mathrm{Rg} 1$. Anal Bioanal Chem 378:1338-1341

52. GINSENG RADIX RUBRA. Japanese Pharmacopoeia 18th Edition (JP18th), 1923-1925. https://www.mhlw.go.jp/conte nt/11120000/000788459.pdf

53. Taranova NA, Byzova NA, Zaiko VV, Starovoitova TA, Vengerov YY, Zherdev AV, Dzantiev BB (2013) Integration of lateral flow and microarray technologies for multiplex immunoassay: application to the determination of drugs of abuse. Microchim Acta 180:1165-1172. https://doi.org/10.1007/ s00604-013-1043-2

54. Wang C, Peng J, Liu DF, Xing KY, Zhang GG, Huang Z, Cheng S, Zhu FF, Duan ML, Zhang KY, Yuan MF, Lai WH (2018) Lateral flow immunoassay integrated with competitive and sandwich models for the detection of aflatoxin M1 and Escherichia coli O157:H7 in milk. J Dairy Sci 101:8767-8777. https://doi.org/ 10.3168/jds.2018-14655

55. Ren YG, Liu MC, Ji MZ, Chen C, Hu HZ, Wang ZX, Yu PQ, Shang JM, Zhou QW, Tao NY, Guo YF, Lu YJ, Wang ZZ (2021) Rapid detection of human heart-type fatty acid-binding protein in human plasma and blood using a colloidal gold-based lateral flow immunoassay. Exp Ther Med 22:1238. https://doi.org/10. 3892/etm.2021.10673

56. Jeffrey PD, Schildbach JF, Chang CYY, Kussie PH, Margolies MN, Sheriff S (1995) Structure and specificity of the anti-digoxinantibody 40-50. J Mol Biol 248:344-360. https://doi.org/10 1016/S0022-2836(95)80055-7

57. Quinton J, Charruault L, Nevers MC, Volland H, Dognon JP, Crémlnon C, Taran F (2010) Toward the limits of sandwich immunoassay of very low molecular weight molecules. Anal Chem 82:2536-2540. https://doi.org/10.1021/ac100058f

58. Teerinen T, Lappalainen T, Erho T (2014) A paper-based lateral flow assay for morphine. Anal Bioanal Chem 406:5955-5965. https://doi.org/10.1007/s00216-014-8001-7

59. Bever CS, Adams CA, Hnasko RM, Cheng LW, Stanker LH (2020) Lateral flow immunoassay (LFIA) for the detection of lethal amatoxins from mushrooms. PLoS ONE 15:e0231781. https://doi.org/10.1371/journal.pone.0231781

60. Parray HA, Shukla S, Samal S, Shrivastava T, Ahmed S, Sharma C, Kumar R (2020) Hybridoma technology a versatile method for isolation of monoclonal antibodies, its applicability across species, limitations, advancement and future perspectives. Int Immunopharmacol 85:106-639

61. Greenfield EA, DeCaprio J, Brahmandam M (2018) Making weak antigens strong: Cross-linking peptides to klh with maleimide. Cold Spring Harb Protoc 2018:810-811. https://doi.org/10. 1101/pdb.prot100016

62. Li B, Yuan Z, Hung HC, Ma J, Jain P, Tsao C, Xie J, Zhang P, Lin X, Wu K, Jiang S (2018) Revealing the immunogenic risk of polymers. Angew Chemie - Int Ed 57:13873-13876. https:// doi.org/10.1002/anie.201808615

63. Kang TH, Seong BL (2020) Solubility, stability, and avidity of recombinant antibody fragments expressed in microorganisms. Front Microbiol 11:1927

64. Sae-Foo W, Krittanai S, Juengsanguanpornsuk W, Yusakul G, Sakamoto S, Putalun W (2021) Fragment antigen-binding (Fab) antibody-based lateral flow immunoassay for rapid and sensitive detection of potent phytoestrogen, deoxymiroestrol. J Nat Med 75:1043-1049

65. Krittanai S, Putalun W, Sakamoto S, Tanaka H, Juengwatanatrakul T, Yusakul G (2020) Expression of actively soluble 
antigen-binding fragment (Fab) antibody and GFP fused Fab in the cytoplasm of the engineered Escherichia coli. Mol Biol Rep 47:4519-4529. https://doi.org/10.1007/s11033-020-05502-7

66. Li X, Chen X, Liu Z, Wang J, Hua Q, Liang J, Shen X, Xu Z, Lei H, Sun Y (2021) Latex microsphere immunochromatography for quantitative detection of dexamethasone in milk and pork. Food Chem 345:128607. https://doi.org/10.1016/j.foodchem.2020. 128607

67. Wiriyachaiporn N, Sirikett H, Maneeprakorn W, Dharakul T (2017) Carbon nanotag based visual detection of influenza A virus by a lateral flow immunoassay. Microchim Acta 184:18271835. https://doi.org/10.1007/s00604-017-2191-6

68. Zhang X, Zhao F, Sun Y, Mi T, Wang L, Li Q, Li J, Ma W, Liu W, Zuo J, Chu X, Chen B, Han W, Mao Y (2020) Development of a highly sensitive lateral flow immunoassay based on receptorantibody-amorphous carbon nanoparticles to detect $22 \beta$-lactams in milk. Sensors Actuators B Chem 321:128458. https://doi.org/ 10.1016/j.snb.2020.128458

69. Noguera P, Posthuma-Trumpie GA, Van Tuil M, Van Der Wal FJ, De Boer A, Moers APHA, Van Amerongen A (2011) Carbon nanoparticles in lateral flow methods to detect genes encoding virulence factors of Shiga toxin-producing Escherichia coli. Anal Bioanal Chem 399:831-838. https://doi.org/10.1007/ s00216-010-4334-z

70. Bai Y, Tian C, Wei X, Wang Y, Wang D, Shi X (2012) A sensitive lateral flow test strip based on silica nanoparticle/CdTe quantum dot composite reporter probes. RSC Adv 2:1778-1781. https://doi.org/10.1039/c2ra00976e

71. Liu F, Zhang H, Wu Z, Dong H, Zhou L, Yang D, Ge Y, Jia C, Liu H, Jin Q, Zhao J, Zhang Q, Mao H (2016) Highly sensitive and selective lateral flow immunoassay based on magnetic nanoparticles for quantitative detection of carcinoembryonic antigen. Talanta 161:205-210. https://doi.org/10.1016/j.talanta.2016.08. 048

72. Wen HW, Borejsza-Wysocki W, Decory TR, Durst RA (2005) Development of a competitive liposome-based lateral flow assay for the rapid detection of the allergenic peanut protein Ara h1. Anal Bioanal Chem 382:1217-1226. https://doi.org/10.1007/ s00216-005-3292-3

73. Calabria D, Calabretta MM, Zangheri M, Marchegiani E, Trozzi I, Guardigli M, Michelini E, Di Nardo F, Anfossi L, Baggiani C, Mirasoli M (2021) Recent advancements in enzyme-based lateral flow immunoassays. Sensors 21:3358

74. Christopher P, Robinson N, Shaw MK (2007) Antibody-label conjugates in lateral-flow assays. Drugs of abuse, pp 87-98

75. Haynes CA, Norde W (1994) Globular proteins at solid/liquid interfaces. Colloids Surf B Biointerfaces 2:517-566

76. Norde W (1996) Driving forces for protein adsorption at solid surfaces. Macromol Symp 103:5-18. https://doi.org/10.1002/ masy. 19961030104

77. Zhang L, Mazouzi Y, Salmain M, Liedberg B, Boujday S (2020) Antibody-gold nanoparticle bioconjugates for biosensors: synthesis, characterization and selected applications. Biosens Bioelectron 165:112-370

78. Cvak B, Pum D, Molinelli A, Krska R (2012) Synthesis and characterization of colloidal gold particles as labels for antibodies as used in lateral flow devices. Analyst 137:1882-1887. https://doi. org/10.1039/c2an16108g

79. Makhsin SR, Razak KA, Noordin R, Zakaria ND, Chun TS (2012) The effects of size and synthesis methods of gold nanoparticle-conjugated $\mathrm{M} \alpha \mathrm{HIgG} 4$ for use in an immunochromatographic strip test to detect brugian filariasis. Nanotechnology 23:495719. https://doi.org/10.1088/0957-4484/23/49/495719

80. Maxwell T, Nogueira Campos MG, Smith S, Doomra M, Thwin Z, Santra S (2019) Quantum dots. Nanoparticles for biomedical applications: fundamental concepts, biological interactions and clinical applications, pp 243-265

81. Wang Y, Xu J, Qiu Y, Li P, Liu B, Yang L, Barnych B, Hammock BD, Zhang C (2019) Highly specific monoclonal antibody and sensitive quantum dot beads-based fluorescence immunochromatographic test strip for tebuconazole assay in agricultural products. J Agric Food Chem 67:9096-9103. https://doi.org/10. 1021/acs.jafc.9b02832

82. Resch-Genger U, Grabolle M, Cavaliere-Jaricot S, Nitschke R, Nann T (2008) Quantum dots versus organic dyes as fluorescent labels. Nat Methods 5:763-775

83. Kaviani D (2015) Synthesis of carbon nanoparticles from polystyrene wastes. Int J Sci 1:53-57. https://doi.org/10.18483/ijsci. 797

84. Muhsan MS, Nadeem S, Hassan AU, Din AMU, Shahid S, Ali S (2019) Synthesis of carbon nanoparticles by using seed oils. Pakistan J Sci Ind Res Ser A Phys Sci 62:1-7. https://doi.org/10. 52763/PJSIR.PHYS.SCI.62.1.2019.1.7

85. Kalogianni DP, Boutsika LM, Kouremenou PG, Christopoulos TK, Ioannou PC (2011) Carbon nano-strings as reporters in lateral flow devices for DNA sensing by hybridization. Anal Bioanal Chem 400:1145-1152. https://doi.org/10.1007/ s00216-011-4845-2

86. Qiu W, Baryeh K, Takalkar S, Chen W, Liu G (2019) Carbon nanotube-based lateral flow immunoassay for ultrasensitive detection of proteins: application to the determination of IgG. Microchim Acta 186:436. https://doi.org/10.1007/ s00604-019-3508-4

87. Posthuma-Trumpie GA, Wichers JH, Koets M, Berendsen LBJM, Van Amerongen A (2012) Amorphous carbon nanoparticles: a versatile label for rapid diagnostic (immuno)assays. Anal Bioanal Chem 402:593-600

88. Suárez-Pantaleón C, Wichers J, Abad-Somovilla A, Van Amerongen A, Abad-Fuentes A (2013) Development of an immunochromatographic assay based on carbon nanoparticles for the determination of the phytoregulator forchlorfenuron. Biosens Bioelectron 42:170-176. https://doi.org/10.1016/j.bios.2012. 11.001

89. Putalun W, Tanaka H, Shoyama Y (2005) Rapid detection of glycyrrhizin by immunochromatograhic assay. Phytochem Anal 16:370-374. https://doi.org/10.1002/pca.862

90. Imsungnoen $\mathrm{N}$, Phrompittayarat $\mathrm{W}$, Ingkaninan $\mathrm{K}$, Tanaka $\mathrm{H}$, Putalun W (2009) Immunochromatographic assay for the detection of pseudojujubogenin glycosides. Phytochem Anal 20:6467. https://doi.org/10.1002/pca.1098

91. Sritularak B, Juengwatanatrakul T, Putalun W, Tanaka H, Morimoto $S$ (2012) A rapid one-step immunochromatographic assay for the detection of asiaticoside. J Nat Med 66:279-283. https:// doi.org/10.1007/s11418-011-0582-2

92. Inyai C, Komaikul J, Kitisripanya T, Tanaka H, Sritularak B, Putalun W (2015) Development of a rapid immunochromatographic strip test for the detection of mulberroside A. Phytochem Anal 26:423-427. https://doi.org/10.1002/pca.2576

93. Sakamoto S, Yusakul G, Pongkitwitoon B, Tanaka H, Morimoto S (2016) Colloidal gold-based indirect competitive immunochromatographic assay for rapid detection of bioactive isoflavone glycosides daidzin and genistin in soy products. Food Chem 194:191-195. https://doi.org/10.1016/j.foodchem.2015.08.002

94. Krittanai S, Kitisripanya T, Udomsin O, Tanaka H, Sakamoto S, Juengwatanatrakul T, Putalun W (2018) Development of a colloidal gold nanoparticle-based immunochromatographic strip for the one-step detection of miroestrol and puerarin. Biomed Chromatogr 32:e4330. https://doi.org/10.1002/bmc.4330

95. Sakamoto S, Wada S, Tanaka H, Morimoto S (2018) Sensitive quantitative analysis of the bitter glycoside amarogentin 
by specific monoclonal antibody-based indirect competitive enzyme-linked immunosorbent assay. RSC Adv 8:17410-17416. https://doi.org/10.1039/c8ra02922a

96. Putalun W, Morinaga O, Tanaka H, Shoyama Y (2004) Development of a one-step immunochromatographic strip test for the detection of sennosides A and B. Phytochem Anal 15:112-116. https://doi.org/10.1002/pca.752

97. Zhao J, He SP, Liu W, Deng AX, Nan TG, Wang BM, Zhai ZX, Li ZH (2006) Development of a lateral flow dipstick immunoassay for the rapid detection of glycyrrhizic acid. Food Agric Immunol 17:173-181. https://doi.org/10.1080/095401006010728 75

98. Paudel MK, Putalun W, Sritularak B, Morinaga O, Shoyama Y, Tanaka H, Morimoto S (2011) Development of a combined technique using a rapid one-step immunochromatographic assay and indirect competitive ELISA for the rapid detection of baicalin. Anal Chim Acta 701:189-193. https://doi.org/10.1016/j.aca. 2011.05.054

99. Limsuwanchote S, Putalun W, Tanaka H, Morimoto S, Keawpradub N, Wungsintaweekul J (2018) Development of an immunochromatographic strip incorporating anti-mitragynine monoclonal antibody conjugated to colloidal gold for Kratom alkaloids detection. Drug Test Anal 10:1168-1175. https://doi. org/10.1002/dta.2354

100. Paudel MK, Shirota O, Sakamoto S, Morimoto S, Tanaka H (2017) An immunochromatographic assay for rapid etection of salvinorin A. J Immunoass Immunochem 38:438-448. https:// doi.org/10.1080/15321819.2017.1324797

101. Smith LC, Lin L, Hwang CS, Zhou B, Kubitz DM, Wang H, Janda KD (2019) Lateral flow assessment and unanticipated toxicity of Kratom. Chem Res Toxicol 32:113-121. https:// doi.org/10.1021/acs.chemrestox.8b00218

102. Phaisan S, Yusakul G, Nuntawong P, Sakamoto S, Putalun W, Morimoto S, Tanaka H (2021) Immunochromatographic assay for the detection of kwakhurin and its application for the identification of Pueraria candollei var. mirifica (Airy Shaw \& Suvat.) Niyomdham. Phytochem Anal 32:503-511. https:// doi.org/10.1002/pca.2998

103. Kitisripanya T, Inyai C, Komaikul J, Krittanai S, Juengwatanatrakul T, Sakamoto S, Tanaka H, Morimoto S, Putalun W (2017) A lateral flow colloidal gold-based immunoassay for rapid detection of miroestrol in samples of White Kwao Krua, a phytoestrogen-rich plant. J Nat Med 71:659-664. https://doi. org/10.1007/s11418-017-1096-3

104. Chaingam J, Kitisripanya T, Krittanai S, Sakamoto S, Tanaka H, Putalun W (2019) Development of a simple and rapid method for the detection of isomiroestrol in Pueraria candollei by an immunochromatographic strip test. J Nat Med 73:577583. https://doi.org/10.1007/s11418-019-01307-6

105. Laitinen MPA, Vuento M (1996) Immunochromatographic assay for quantitation of milk progesterone. Acta Chem Scand 50:141-145. https://doi.org/10.3891/acta.chem.scand.50-0141

106. Nan TG, Cao Z, He LS, Yuan Y, Huang LQ, Wang BM (2013) Development of a lateral flow dipstick immunoassay for rapid detection of ginsenoside Re. Zhongguo Zhongyao Zazhi 38:2586-2589. https://doi.org/10.4268/cjcmm20131608

107. Tanaka H, Fukuda N, Shoyama Y (1999) Formation of monoclonal antibody against a major ginseng component, ginsenoside Rb1 and its characterization. Cytotechnology 29:115-120. https://doi.org/10.1023/A:1008068718392

108. Fukuda N, Tanaka H, Shoyama Y (2000) Formation of monoclonal antibody against a major ginseng component, ginsenoside $\operatorname{Rg} 1$ and its characterization: Monoclonal antibody for a ginseng saponin. Cytotechnology 34:197-204. https://doi.org/ 10.1023/A: 1008162703957
109. Morinaga O, Tanaka H, Shoyama Y (2000) Production of monoclonal antibody against a major purgative component, sennoside A, its characterization and ELISA. Analyst 125:11091113. https://doi.org/10.1039/b0009881

110. Morinaga O, Nakajima S, Tanaka H, Shoyama Y (2001) Production of monoclonal antibodies against a major purgative component, sennoside $\mathrm{B}$, their characterization and use in ELISA. Analyst 126:1372-1376. https://doi.org/10.1039/b1031 $53 \mathrm{~h}$

111. Tanaka H, Shoyama Y (1998) Formation of a monoclonal antibody against glycyrrhizin and development of an ELISA. Biol Pharm Bull 21:1391-1393. https://doi.org/10.1248/bpb.21.1391

112. Phrompittayarat W, Putalun W, Tanaka H, Jetiyanon K, WlttayaAreekul S, Ingkaninan K (2007) Determination of pseudojujubogenin glycosides from Brahmi based on immunoassay using a monoclonal antibody against bacopaside I. Phytochem Anal 18:411-418. https://doi.org/10.1002/pca.996

113. Juengwatanatrakul T, Sritularak B, Amornnopparattanakul P, Tassanawat P, Putalun W, Tanaka H, Morimoto S (2011) Preparation of a specific monoclonal antibody to asiaticoside for the development of an enzyme-linked immunosorbent assay. Analyst 136:1013-1017. https://doi.org/10.1039/c0an00868k

114. Morinaga O, Tanaka H, Shoyama Y (2006) Enzyme-linked immunosorbent assay for the determination of total ginsenosides in ginseng. Anal Lett 39:287-296. https://doi.org/10.1080/00032 710500476979

115. Komaikul J, Kitisripanya T, Tanaka H, Sritularak B, Putalun W (2014) Development of an enzyme-linked immunosorbent assay for specific detection of mulberroside A in mulberry (Morus alba L.) using anti-mulberroside a polyclonal antibody. Food Anal Methods 7:58-63. https://doi.org/10.1007/s12161-013-9598-4

116. Sakamoto S, Yusakul G, Pongkitwitoon B, Paudel MK, Tanaka $\mathrm{H}$, Morimoto S (2015) Simultaneous determination of soy isoflavone glycosides, daidzin and genistin by monoclonal antibodybased highly sensitive indirect competitive enzyme-linked immunosorbent assay. Food Chem 169:127-133. https://doi.org/10. 1016/j.foodchem.2014.08.004

117. Kitisripanya T, Krittanai S, Udomsin O, Jutathis K, Komaikul J, Juengwatanatrakul T, Sakamoto S, Tanaka H, Morimoto S, Putalun W (2017) Development of an enzyme-linked immunosorbent assay for determination of miroestrol using an anti-miroestrol monoclonal antibody. Planta Med 83:855-861. https://doi.org/ 10.1055/s-0043-102689

118. Sakamoto S, Yusakul G, Tsuneura Y, Putalun W, Usui K, Miyamoto T, Tanaka H, Morimoto S (2017) Sodium periodate-mediated conjugation of harringtonine enabling the production of a highly specific monoclonal antibody, and the development of a sensitive quantitative analysis method. Analyst 142:1140-1148. https://doi.org/10.1039/c6an02751b

119. Sakamoto S, Nagamitsu R, Yusakul G, Miyamoto T, Tanaka H, Morimoto S (2017) Ultrasensitive immunoassay for monocrotaline using monoclonal antibody produced by $N, N^{\prime}$-carbonyldiimidazole mediated hapten-carrier protein conjugates. Talanta 168:67-72. https://doi.org/10.1016/j.talanta.2017.03.028

120. Limsuwanchote S, Wungsintaweekul J, Keawpradub N, Putalun W, Morimoto S, Tanaka H (2015) Development of indirect competitive ELISA for quantification of mitragynine in Kratom (Mitragyna speciosa (Roxb.) Korth.). Forensic Sci Int 244:7077. https://doi.org/10.1016/j.forsciint.2014.08.011

121. Paudel MK, Shirota O, Sasaki-Tabata K, Tanaka H, Sekita S, Morimoto S (2013) Development of an enzyme immunoassay using a monoclonal antibody against the psychoactive diterpenoid salvinorin A. J Nat Prod 76:1654-1660. https://doi.org/10. 1021/np400358n

122. Udomsin O, Krittanai S, Kitisripanya T, Tanaka H, Putalun W (2017) A new highly selective and specific anti-puerarin 
polyclonal antibody for determination of puerarin using a mannich reaction hapten conjugate. Pharmacogn Mag 13:S845-S851. https://doi.org/10.4103/pm.pm_276_17

123. Sai J, Zhao Y, Shan W, Qu B, Zhang Y, Cheng J, Qu H, Wang Q (2016) Development of an enzyme-linked immunosorbent assay and immunoaffinity column chromatography for saikosaponin $\mathrm{d}$ using an anti-saikosaponin d monoclonal antibody. Planta Med 82:432-439. https://doi.org/10.1055/s-0035-1568182

124. Kitisripanya $\mathrm{T}$, Jutathis $\mathrm{K}$, Inyai $\mathrm{C}$, Komaikul J, Udomsin O, Tanaka H, Putalun W (2017) Development of an enzyme-linked immunosorbent assay for the detection of isomiroestrol, an identical marker, in White Kwao Krua using a monoclonal antibody. J Pharm Biomed Anal 137:229-234. https://doi.org/10.1016/j. jpba.2017.01.040

125. Yusakul G, Togita R, Minami K, Chanpokapaiboon K, Juengwatanatrakul T, Putalun W, Tanaka H, Sakamoto S, Morimoto S (2019) An indirect competitive enzyme-linked immunosorbent assay toward the standardization of Pueraria candollei based on its unique isoflavonoid, kwakhurin. Fitoterapia 133:23-28. https://doi.org/10.1016/j.fitote.2018.12.010

126. Nuntawong P, Tanaka H, Sakamoto S, Morimoto S (2020) ELISA for the detection of the prohibited doping agent higenamine. Planta Med 86:760-766. https://doi.org/10.1055/a-1181-2084

127. Sae-Foo W, Krittanai S, Juengsanguanpornsuk W, Yusakul G, Kitisripanya T, Sakamoto S, Putalun W (2021) Enzyme-linked immunosorbent assay using fragment antigen-binding (Fab) antibody for determination of deoxymiroestrol, a potent phytoestrogen from Pueraria candollei. Food Agric Immunol 32:336-348. https://doi.org/10.1080/09540105.2021.1946486

128. Liu C, Wang Y, Zhang L, Qin J, Dou X, Fu Y, Li Q, Zhao $X$, Yang M (2020) An integrated strategy for rapid on-site screening and determination of prometryn residues in herbs. Anal Bioanal Chem 412:621-633. https://doi.org/10.1007/ s00216-019-02224-z

129. Li Y, Liu L, Song S, Kuang H (2018) Development of a gold nanoparticle immunochromatographic assay for the on-site analysis of 6-benzylaminopurine residues in bean sprouts. Food Agric Immunol 29:14-26. https://doi.org/10.1080/09540105. 2017.1354359

130. Ding Y, Hua X, Chen H, Gonzalez-Sapienza G, Barnych B, Liu F, Wang M, Hammock BD (2019) A dual signal immunochromatographic strip for the detection of imidaclothiz using a recombinant fluorescent-peptide tracer and gold nanoparticles. Sensors Actuators B Chem 297:126714. https://doi.org/10.1016/j.snb. 2019.126714

131. Yao L, Liu L, Song S, Kuang H, Xu C (2017) Development of indirect competitive enzyme-linked immunosorbent and immunochromatographic strip assays for carbofuran detection in fruits and vegetables. Food Agric Immunol 28:639-651. https://doi. org/10.1080/09540105.2017.1309359

132. Chen ZJ, Wu HL, Xiao ZL, Fu HJ, Shen YD, Luo L, Wang H, Lei HT, Hongsibsong S, Xu ZL (2021) Rational hapten design to produce high-quality antibodies against carbamate pesticides and development of immunochromatographic assays for simultaneous pesticide screening. J Hazard Mater 412:125241. https://doi. org/10.1016/j.jhazmat.2021.125241

133. Liu B, Gong H, Wang Y, Zhang X, Li P, Qiu Y, Wang L, Hua X, Guo Y, Wang M, Liu F, Liu X, Zhang C (2018) A gold immunochromatographic assay for simultaneous detection of parathion and triazophos in agricultural products. Anal Methods 10:422428. https://doi.org/10.1039/c7ay02481a

134. Wang YD, Qin JA, Wu L, Wang BM, Eremin S, Yang SH, Yang $\mathrm{MH}$ (2021) Enzyme-linked immunosorbent assay and immunochromatographic strip for rapid detection of atrazine in three medicinal herbal roots. World J Tradit Chinese Med 7:97-103. https://doi.org/10.4103/wjtcm.wjtcm_76_20

Publisher's Note Springer Nature remains neutral with regard to jurisdictional claims in published maps and institutional affiliations. 